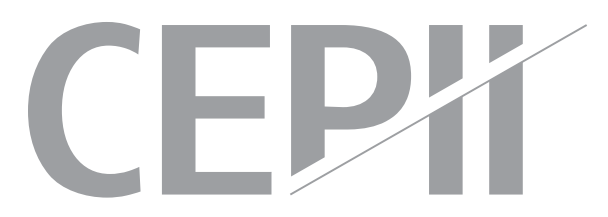

\title{
From Micro to Macro: Demand, Supply, and Heterogeneity in the Trade Elasticity
}

Maria Bas, Thierry Mayer \& Mathias Thoenig

Highlights

- We show that heterogeneity in firm performance generates heterogeneous aggregate trade elasticities under distributions other than the Pareto.

- We estimate firm-level trade elasticity to tariffs, with an average value around -5 .

- Predictions of the model with a log-normal distribution dominate predictions arising with Pareto. 


\section{Abstract}

Models of heterogeneous firms with selection into export market participation generically exhibit aggregate trade elasticities that vary across country-pairs. Only when heterogeneity is assumed Pareto-distributed do all elasticities collapse into an unique elasticity, estimable with a gravity equation. This paper provides a theory-based method for quantifying country-pair specific elasticities when moving away from Pareto, i.e. when gravity does not hold. Combining two firm-level customs datasets for which we observe French and Chinese individual sales on the same destination market over the 2000-2006 period, we are able to estimate all the components of the dyadic elasticity: i) the demand-side parameter that governs the intensive margin and ii) the supply side parameters that drive the extensive margin. These components are then assembled under theoretical guidance to calculate bilateral aggregate elasticities over the whole set of destinations, and their decomposition into different margins. Our predictions fit well with econometric estimates, supporting our view that micro-data is a key element in the quantification of non-constant macro trade elasticities.

\section{Keywords}

Trade elasticity, Firm-level data, Heterogeneity, Gravity, Pareto, Log-normal.

\section{JEL}

F21.

\section{Working Paper}

\section{CEPI}

CEPII (Centre d'Etudes Prospectives et d'Informations Internationales) is a French institute dedicated to producing independent, policyoriented economic research helpful to understand the international economic environment and challenges in the areas of trade policy, competitiveness, macroeconomics, international finance and growth.
CEPII Working Paper

Contributing to research in international economics

C C CEPII, PARIS, 2015

All rights reserved. Opinions expressed in this publication are those of the author(s) alone.

$\begin{array}{ll}\text { Editorial Director: } & \text { CEPII } \\ \text { Sébastien Jean } & \text { 113, rue de Grenelle } \\ & 75007 \text { Paris } \\ \text { Production: } & +33153685500 \\ \text { Laure Boivin } & \\ \text { No ISSN: } 1293-2574 & \text { Prw.cepii.fr }\end{array}$




\section{Introduction}

The response of trade flows to a change in trade costs, the aggregate trade elasticity, is a central element in any evaluation of the welfare impacts of trade liberalization. Arkolakis et al. (2012) recently showed that this parameter, denoted $\varepsilon$ for the rest of the paper, is actually one of the (only) two sufficient statistics needed to calculate Gains From Trade (GFT) under a surprisingly large set of alternative modeling assumptions - the ones most commonly used by recent research in the field. Measuring those elasticities has therefore been the topic of a long-standing literature in international economics. ${ }^{1}$ The most common usage (and the one recommended by Arkolakis et al., 2012) is to estimate this elasticity in a macro-level bilateral trade equation that Head and Mayer (2014) label structural gravity. In order for this estimate of $\varepsilon$ to be relevant for a particular experiment of trade liberalization, it is crucial for this bilateral trade equation to be correctly specified as a structural gravity model with, in particular, a unique elasticity to be estimated across dyads.

Our starting point is that the model of heterogeneous firms with selection into export market participation (Melitz, 2003) will in general exhibit a dyad-specific elasticity, i.e. an $\varepsilon_{n i}$, which applies to each country pair. Only when heterogeneity is assumed Pareto-distributed do all $\varepsilon_{n i}$ collapse to a single $\varepsilon$. Under any other distributional assumption, obtaining an estimate of the aggregate trade elasticity from a macro-level bilateral trade equation becomes problematic, since there is a now a whole set of $\varepsilon_{n i}$ to be estimated, and structural gravity does not hold anymore. We argue that in this case quantifying trade elasticities at the aggregate level makes it necessary to use micro-level information. To this purpose we exploit a rich panel that combines sales of French and Chinese exporters over 2000-2006 on many destination-product combinations for which we also observe the applied tariff. We propose a theory-based method using this firm-level export data for estimating all the components of the dyad-specific trade elasticity: i) the demand-side parameter that governs the intensive margin and ii) the supply side parameters that drive the extensive margin. These components are then assembled under theoretical guidance to calculate the dyadic aggregate elasticities over the whole set of destination-product.

Taking into account cross-dyadic heterogeneity in trade elasticities is crucial for quantifying the expected impact of various trade policy experiments. Consider the example of the current negotiations over a transatlantic trade agreement between the USA and the EU (TTIP). Under the simplifying assumption of a unique elasticity, whether the trade liberalization takes place with a proximate vs distant, large vs small economy, etc. is irrelevant in terms of trade-promoting effect or welfare gains calculations. By contrast, our results suggest that the relevant $\varepsilon_{n i}$ should be smaller (in absolute value) than if the United States were considering a comparable agreement with countries where the expected volume of trade is smaller. Regarding welfare, Melitz and Redding (2015) and Head et al. (2014) have shown theoretically that the GFT can be quite substantially

\footnotetext{
${ }^{1}$ Recent debates in this literature have concerned the choice of an appropriate source of identification (exchange rate versus tariff changes in particular), aggregation issues (Imbs and Méjean, 2014; Ossa, 2012, for instance), and how those elasticities might vary according to the theoretical model at hand (Simonovska and Waugh, 2012).
} 
mis-estimated if one assumes a constant trade elasticity when the "true" elasticity is variable (the margin of error can exceed 100 percent in both papers). The expected changes in trade patterns and welfare effects of agreements such as TTIP will therefore be different compared to the unique elasticity case. One of the main objectives of our paper is to quantify how wrong can one be when making predictions based on a constant trade elasticity assumption.

Our approach maintains the traditional CES $(\sigma)$ demand system combined with monopolistic competition. It features several steps that are structured around the following decomposition of aggregate trade elasticity into the sum of the intensive margin and the (weighted) extensive margin:

$$
\varepsilon_{n i}=\underbrace{1-\sigma}_{\text {intensive margin }}+\underbrace{\frac{1}{\bar{x}_{n i} / x_{n i}^{\mathrm{MIN}}}}_{\text {min-to-mean }} \times \underbrace{\frac{d \ln N_{n i}}{d \ln \tau_{n i}}}_{\text {extensive margin }},
$$

The weight is the mean-to-min ratio, our observable measuring the dyadic dispersion of firm-level performance, that is defined as the ratio of average to minimum sales across markets. Intuitively, the weight of the extensive margin should be decreasing in easy markets where the increasing presence of weaker firms augments productivity dispersion. When assuming Pareto with shape parameter $\theta$, the last part of the elasticity reduces to $\sigma-1-\theta$, and the overall elasticity becomes constant and reflects only the supply side homogeneity in the distribution of productivity: $\varepsilon_{n i}^{P}=$ $\varepsilon^{P}=-\theta$ (Chaney, 2008).

Our first step aims to estimate the demand side parameter $\sigma$ using firm-level exports. Since protection is imposed on all firms from a given origin, higher demand and lower protection are not separately identifiable when using only one country of exports. With CES, firms are all confronted to the same aggregate demand conditions. Thus, considering a second country of origin enables to isolate the effects of trade policy, if the latter is discriminatory. We therefore combine shipments by French and Chinese exporters to destinations that confront those firms with different levels of tariffs. Our setup yields a firm-level gravity equation specified as a ratio-type estimation so as to eliminate unobserved characteristics of both the exporting firm and the importer country, while keeping tariffs in the regression. This approach is in many ways akin to using high-dimensional fixed effects, with the big advantage of easing the computational burden in our context that includes many firms exporting to numerous destinations. This method is called tetrads by Head et al. (2010) since it combines a set of four trade flows into an ratio of ratios called an export tetrad and regresses it on a corresponding tariff tetrad for the same product-country combinations. ${ }^{2}$ Our identification strategy relies on there being enough variation in tariffs applied by different destination markets to French and Chinese exporters. We therefore use in our main specification the last year before the entry of China into WTO in 2001 in cross-section estimations. We also exploit the

\footnotetext{
${ }^{2}$ Other work in the literature also relies on the ratio of ratios estimation. Romalis (2007) uses a similar method to estimate the effect of tariffs on trade flows at the product-country level. He estimates the effects of applied tariff changes within NAFTA countries (Canada and Mexico) on US imports at the product level. Hallak (2006) estimates a fixed effects gravity model and then uses a ratio of ratios method in a quantification exercise. Caliendo and Parro (2015) also use ratios of ratios and rely on asymmetries in tariffs to identify industry-level elasticities.
} 
panel dimension of the data over the 2000-2006 period. We explore different sources of variance in the data with comparable estimates of the intensive margin trade elasticity that imply an average value of $\sigma$ around 5 .

Our second step applies equation (1) and assembles the estimates of the intensive margin $(\hat{\sigma})$ with the central supply side parameter — reflecting dispersion in the distribution of productivityestimated on the same datasets, to obtain predicted aggregate elasticities of total export, number of exporters and average exports to each destination. Those dyadic predictions (one elasticity for each exporter-importer combination) require knowledge of the bilateral export productivity cutoff under which firms find exports to be unprofitable. We also make use of the mean-to-min ratio to reveal those cutoffs. A key element of our procedure is the calibration of the productivity distribution. As an alternative to Pareto we consider the log-normal distribution that fits the micro-data on firm-level sales very well. We show that under log-normal the $\varepsilon_{n i}$ are larger (in absolute value) for pairs with low volumes of trade. Hence the trade-promoting impact of liberalization is expected to be larger for this kind of trade partners. A side result of our paper is to discriminate between Pareto and log-normal as potential distributions for the underlying firm-level heterogeneity, suggesting that log-normal does a better job at matching the non-unique response of exports to changes in trade costs. Two pieces of evidence in that direction are provided. ${ }^{3}$ The first provides direct evidence that aggregate elasticities are non-constant across dyads. The second is a positive and statistically significant correlation across industries between firm-level and aggregate elasticities-at odds with the prediction of a null correlation under Pareto. We also find that the heterogeneity in trade elasticities is quantitatively important: Although the cross-dyadic average of bilateral elasticities is quite well approximated by a standard gravity model constraining the estimated parameter to be constant, deviations from this average level can be large. For Chinese exports, assuming a unique elasticity would yield to underestimate the trade impact of a tariff liberalization by about 25\% for countries with initially very small trade flows (Somalia, Chad or Azerbaijan for instance). By contrast, the error would be to overestimate by around 12.5 percent the exports created when the United States or Japan reduce their trade costs.

Our paper clearly fits into the empirical literature estimating trade elasticities. Different approaches and proxies for trade costs have been used, with an almost exclusive focus on aggregate country or industry-level data. The gravity approach to estimating those elasticities mostly uses tariff data to estimate bilateral responses to variation in applied tariff levels. Most of the time, identification is in the cross-section of country pairs, with origin and destination determinants being controlled through fixed effects (Baier and Bergstrand (2001), Head and Ries (2001), Caliendo and Parro (2015), Hummels (1999), Romalis (2007) are examples). A related approach is to use the fact that most foundations of gravity have the same coefficient on trade costs and domestic cost

\footnotetext{
${ }^{3} \mathrm{Head}$ et al. (2014) provide evidence and references for several micro-level datasets that individual sales are much better approximated by a log-normal distribution when the entire distribution is considered (without left-tail truncation). Freund and Pierola (2015) is a recent example showing very large deviations from the Pareto distribution if the data is not vastly truncated for all of the 32 countries used. Our findings complement those papers by providing industryand aggregate-level evidence on trade elasticities.
} 
shifters to estimate that elasticity from the effect on bilateral trade of exporter-specific changes in productivity, export prices or exchange rates (Costinot et al. (2012) is a recent example). ${ }^{4}$ Baier and Bergstrand (2001) find a demand side elasticity ranging from -4 to -2 using aggregate bilateral trade flows from 1958 to 1988. Using product-level information on trade flows and tariffs, this elasticity is estimated by Head and Ries (2001), Romalis (2007) and Caliendo and Parro (2015) with benchmark average elasticities of $-6.88,-8.5$ and -4.45 respectively. Costinot et al. (2012) also use industry-level data for OECD countries, and obtains a preferred elasticity of -6.53 using productivity based on producer prices of the exporter as the identifying variable. Our paper also has consequences for how to interpret those numbers in terms of underlying structural parameters. With a homogeneous firms model of the Krugman (1980) type in mind, the estimated elasticity turns out to reveal a demand-side parameter only (this is also the case with Armington differentiation and perfect competition as in Anderson and van Wincoop (2003)). When instead considering heterogeneous firms à la Melitz (2003), the literature has proposed that the macro-level trade elasticity is driven solely by a supply-side parameter describing the dispersion of the underlying heterogeneity distribution of firms. This result has been shown with several demand systems (CES by Chaney (2008), linear by Melitz and Ottaviano (2008), translog by Arkolakis et al. (2010) for instance), but again relies critically on the assumption of a Pareto distribution. The trade elasticity then provides an estimate of the dispersion parameter of the Pareto. ${ }^{5}$ We show here that both existing interpretations of the estimated elasticities are too extreme: When the Pareto assumption is relaxed, the aggregate trade elasticity is a mix of demand and supply parameters.

There is a small set of papers-the most related to the first part of ours-that estimate the intensive margin elasticity at the firm-level. Berman et al. (2012) presents estimates of the trade elasticity with respect to real exchange rate variations across countries and over time using firm-level data from France. Fitzgerald and Haller (2014) use firm-level data from Ireland, real exchange rate and weighted average firm-level applied tariffs as price shifters to estimate the trade elasticity to trade costs. The results for the impact of real exchange rate on firms' export sales are of a similar magnitude, around 0.8 to 1 . Applied tariffs vary at the product-destination-year level. Fitzgerald and Haller (2014) create a firm-level destination tariff as the weighted average over all hs6 products exported by a firm to a destination in a year using export sales as weights. Relying on this construction, they find a tariff elasticity of around -2.5 at the micro level. This is also the preferred estimates of Berthou and Fontagné (2015), who use the response of the largest French exporters in the United States to the levels of applied tariffs. We depart from those papers by

\footnotetext{
${ }^{4}$ Other methodologies (also used for aggregate elasticities) use identification via heteroskedasticity in bilateral flows, and have been developed by Feenstra (1994) and applied widely by Broda and Weinstein (2006) and Imbs and Méjean (2014). Yet another alternative is to proxy trade costs using retail price gaps and their impact on trade volumes, as proposed by Eaton and Kortum (2002) and extended by Simonovska and Waugh (2011).

${ }^{5}$ This result of a constant trade elasticity reflecting the Pareto shape holds when maintaining the CES demand system but making other improvements to the model such as heterogeneous marketing and/or fixed export costs (Arkolakis, 2010; Eaton et al., 2011). In the Ricardian setup of Eaton and Kortum (2002), the trade elasticity is also a (constant) supply side parameter reflecting heterogeneity, but this heterogeneity takes place at the national level, and reflects the scope for comparative advantage.
} 
using an alternative methodology to identify the trade elasticity with respect to applied tariffs; i.e. the differential treatment of exporters from two distinct countries (France and China) in a set of product-destination markets.

Our paper also contributes to the literature studying the importance of the distribution assumption of heterogeneity for trade patterns, trade elasticities and welfare. Head et al. (2014), Yang (2014), Melitz and Redding (2015) and Feenstra (2013) have recently argued that the simple gains from trade formula proposed by Arkolakis et al. (2012) relies crucially on the Pareto assumption, which mutes important channels of gains in the heterogenous firms case. Barba Navaretti et al. (2015) present gravity-based evidence that the exporting country fixed effects depends on characteristics of firms' distribution that go beyond the simple mean productivity, a feature incompatible with the usually specified Pareto heterogeneity. The alternatives to Pareto considered to date in welfare gains quantification exercises are i) the truncated Pareto by Helpman et al. (2008), Melitz and Redding (2015) and Feenstra (2013), and ii) the log-normal by Head et al. (2014) and Yang (2014). A key simplifying feature of Pareto is to yield a constant trade elasticity, which is not the case for alternative distributions. Helpman et al. (2008) and Novy (2013) have produced gravitybased evidence showing substantial variation in the trade cost elasticity across country pairs. Our contribution to that literature is to use the estimated demand and supply-side parameters to construct predicted bilateral elasticities for aggregate flows under the log-normal assumption, and compare their first moments to gravity-based estimates. It is possible to generate bilateral trade elasticities changing another feature of the standard model. The most obvious is to depart from the simple CES demand system. Novy (2013) builds on Feenstra (2003), using the translog demand system with homogeneous firms to obtain variable trade elasticities. Atkeson and Burstein (2008) is another example maintaining CES demand, and generating heterogeneity in elasticities trough monopolistic competition. We choose here to keep the change with respect to the benchmark Melitz/Chaney framework to a minimal extent, keeping CES and monopolistic competition, while changing only the distributional assumption.

The next section of the paper describes our model and empirical strategy. The third section presents the different firm-level data and the product-country level tariff data used in the empirical analysis. The fourth section reports the estimates of the intensive margin elasticity. Section 5 computes predicted macro-level trade elasticities and compares them with estimates from the Chinese and French aggregate export data. It also provides two additional pieces of evidence in favor of non-constant trade elasticities. The final section concludes.

\section{Empirical strategy for estimating the demand side parameter}

\subsection{A firm-level export equation}

Consider a set of potential exporting firms, all located in the same origin country $i$ and producing product $p$ (omitting those indexes for the start of exposition). We use the Melitz (2003)/Chaney (2008) theoretical framework of heterogeneous firms facing constant price elasticity demand (CES 
utility combined with iceberg costs) and contemplating exports to several destinations. In this setup, firm-level exports to country $n$ depend upon the firm-specific unit input requirement $(\alpha)$, wages $(w)$, and "real" expenditure in $n, X_{n} P_{n}^{\sigma-1}$, with $P_{n}$ the ideal CES price index relevant for sales in $n$. There are trade costs associated with reaching market $n$, consisting of an observable iceberg-type part $\left(\tau_{n}\right)$, and a shock that affects firms differently on each market, $b_{n}(\alpha):{ }^{6}$

$$
x_{n}(\alpha)=\left(\frac{\sigma}{\sigma-1}\right)^{1-\sigma}\left[\alpha w \tau_{n} b_{n}(\alpha)\right]^{1-\sigma} \frac{X_{n}}{P_{n}^{1-\sigma}}
$$

Taking logs of equation (2), and noting with $\epsilon_{n}(\alpha) \equiv b_{n}^{1-\sigma}$ our unobservable firm-destination error term, and with $A_{n} \equiv X_{n} P_{n}^{\sigma-1}$ the "attractiveness" of country $n$ (expenditure discounted by the degree of competition on this market), a firm-level gravity equation can be derived:

$$
\ln x_{n}(\alpha)=(1-\sigma) \ln \left(\frac{\sigma}{\sigma-1}\right)+(1-\sigma) \ln (\alpha w)+(1-\sigma) \ln \tau_{n}+\ln A_{n}+\ln \epsilon_{n}(\alpha)
$$

Our objective is to estimate the trade elasticity, $1-\sigma$ identified on cross-country differences in applied tariffs (that are part of $\tau_{n}$ ). This involves controlling for a number of other determinants ("nuisance" terms) in equation (3). First, it is problematic to proxy for $A_{n}$, since it includes the ideal CES price index $P_{n}$, which is a complex non-linear construction that itself requires knowledge of $\sigma$. A well-known solution used in the gravity literature is to capture $\left(A_{n}\right)$ with destination country fixed effects (which also solves any issue arising from omitted unobservable $n$-specific determinants). This is however not applicable here since $A_{n}$ and $\tau_{n}$ vary across the same dimension. To separate those two determinants, we use a second set of exporters, based in a country that faces different levels of applied tariffs, such that we recover a bilateral dimension on $\tau$. The firm-level sales become

$$
\ln x_{n i}(\alpha)=(1-\sigma) \ln \left(\frac{\sigma}{\sigma-1}\right)+(1-\sigma) \ln \left(\alpha w_{i}\right)+(1-\sigma) \ln \tau_{n i}+\ln A_{n}+\ln \epsilon_{n i}(\alpha),
$$

where each firm can now be based in one of the two origin countries for which we have customs data, France and China, $i=[\mathrm{FR}, \mathrm{CN}]$. A second issue is that we need to control for firm-level marginal costs $\left(\alpha w_{i}\right)$. Again measures of firm-level productivity and wages are hard to obtain for two different source countries on an exhaustive basis. In addition, there might be a myriad of other firm-level determinants of export performance, such as quality of products exported, managerial capabilities... which will remain unobservable. Capturing those determinants through fixed effects is an option which proves computationally intensive in our case, since we have a very large panel of exporters that export many products to a large number of countries. We adopt an alternative approach, a ratio-type estimation inspired by Hallak (2006), Romalis (2007), Head et al. (2010), and Caliendo and Parro (2015) that removes observable and unobservable determinants for both

\footnotetext{
${ }^{6}$ An example of such unobservable term would be the presence of workers from country $n$ in firm $\alpha$, that would increase the internal knowledge on how to reach consumers in $n$, and therefore reduce trade costs for that specific company in that particular market ( $b$ being a mnemonic for barrier to trade). Note that this type of random shock is isomorphic to assuming a firm-destination demand shock in this CES-monopolistic competition model.
} 
firm-level and destination factors. This method uses four individual export flows to calculate ratios of ratios: an approach referred to as tetrads from now on. We now turn to a presentation of this method.

\subsection{Microfoundations of a ratio-type estimation}

To implement tetrads at the micro level, we need firm-level datasets for two origin countries reporting exports by firm, product and destination country. We also require information on bilateral trade costs faced by firms when selling their products abroad that differ across exporting countries. We combine French and Chinese firm-level datasets from the corresponding customs administration which report export value by firm at the hs6 level for all destinations in 2000 . The firm-level customs datasets are matched with data on tariffs effectively applied to each exporting country (China and France) at the same level of product disaggregation for each destination. Focusing on 2000 allows us to exploit variation in tariffs applied to each exporter country (France/China) at the product level by the importer countries since it precedes the entry of China into WTO at the end of 2001. We also exploit the variation over time of tariffs applied to France and China within products and destinations, from 2000 to 2006 in a set of robustness checks.

Estimating micro-level tetrads implies dividing product-level exports of a firm located in France to country $n$ by the exports of the same product by that same firm to a reference country, denoted $k$. Then, calculate a similar ratio for a Chinese exporter (same product and countries). Finally the ratio of those two ratios uses the multiplicative nature of the CES demand system to get rid of all the "nuisance" terms mentioned above. Because there is quite a large number of exporters, taking all possible firm-destination-product combinations is not feasible. We therefore concentrate our identification on the largest exporters for each product. ${ }^{7}$ We rank firms based on export value for each hs6 product and reference importer country (Australia, Canada, Germany, Italy, Japan, New Zealand, Poland and the UK). ${ }^{8}$ For a given product, taking the ratio of exports of a French firm with rank $j$ exporting to country $n$, over the flow to the reference importer country $k$, removes the need to proxy for firm-level characteristics in equation (4):

$$
\frac{x_{n}\left(\alpha_{j, \mathrm{FR}}\right)}{x_{k}\left(\alpha_{j, \mathrm{FR}}\right)}=\left(\frac{\tau_{n \mathrm{FR}}}{\tau_{k \mathrm{FR}}}\right)^{1-\sigma} \times \frac{A_{n}}{A_{k}} \times \frac{\epsilon_{n}\left(\alpha_{j, \mathrm{FR}}\right)}{\epsilon_{k}\left(\alpha_{j, \mathrm{FR}}\right)}
$$

To eliminate the aggregate attributes of importing countries $n$ and $k$, we need the two sources of firm-level exports to have information on sales by destination country. This allows to take the ratio of equation (5) over the same ratio for a firm with rank $j$ located in China:

$$
\frac{x_{n}\left(\alpha_{j, \mathrm{FR}}\right) / x_{k}\left(\alpha_{j, \mathrm{FR}}\right)}{x_{n}\left(\alpha_{j, \mathrm{CN}}\right) / x_{k}\left(\alpha_{j, \mathrm{CN}}\right)}=\left(\frac{\tau_{n \mathrm{FR}} / \tau_{k \mathrm{FR}}}{\tau_{n \mathrm{CN}} / \tau_{k \mathrm{CN}}}\right)^{1-\sigma} \times \frac{\epsilon_{n}\left(\alpha_{j, \mathrm{FR}}\right) / \epsilon_{k}\left(\alpha_{j, \mathrm{FR}}\right)}{\epsilon_{n}\left(\alpha_{j, \mathrm{CN}}\right) / \epsilon_{k}\left(\alpha_{j, \mathrm{CN}}\right)} .
$$

\footnotetext{
${ }^{7}$ Section A.8.3. presents an alternative strategy that keeps all exporters and explicitly takes into account selection issues.

${ }^{8}$ Those are among the main trading partners of France and China, and also have the key advantage for us of applying different tariff rates to French and Chinese exporters in 2000.
} 
Denoting tetradic terms with a symbol, one can re-write equation (6) as

$$
\tilde{x}_{\{j, n, k\}}=\widetilde{\tau}_{\{n, k\}}^{1-\sigma} \times \widetilde{\epsilon}_{\{j, n, k\}},
$$

which will be our main foundation for estimation.

\subsection{Estimating equation}

With equation (7), we can use tariffs to identify the firm-level trade elasticity, $1-\sigma$. Restoring the product subscript $(p)$, and using $i=\mathrm{FR}$ or $\mathrm{CN}$ as the origin country index, we specify bilateral trade costs as a function of applied tariffs, with ad valorem rate $t_{n i}^{p}$ and of a collection of other barriers, denoted with $D_{n i}$. Those include the classical gravity covariates such as distance, common language, colonial link and common border. Taking the example of a continuous variable such as distance for $D_{n i}$ :

$$
\tau_{n i}^{p}=\left(1+t_{n i}^{p}\right) D_{n i}^{\delta}
$$

which, once introduced in the logged version of (7) leads to our estimable equation

$$
\ln \widetilde{x}_{\{j, n, k\}}^{p}=(1-\sigma) \ln \left(\widetilde{1+t_{\{n, k\}}^{p}}\right)+(1-\sigma) \delta \ln \widetilde{D_{\{n, k\}}}+\ln \widetilde{\epsilon}_{\{j, n, k\}}^{p} .
$$

The dependent variable corresponds to the ratio of ratios of exports for a certain rank $j$. In order to obtain a valid observation for each product, we iterate from $j=1$ to 10 , that is firms ranking from the top to the 10th exporter for a given product. Our precise procedure is the following: Firms are ranked according to their export value for each product and reference importer country $k$. We then take the tetrad of exports of the top French firm over the top Chinese firm exporting the same product to the same destination. The set of destinations for each product is therefore limited to the countries where both the top French and Chinese firm export that product, in addition to the reference country. In order to have enough variation in the dependent variable, we fill in the missing export values of each product-destination-reference with lower ranked export tetrads (until rank 10): For each product $\times$ destination $\times$ reference, we start with the top Chinese exporter $(j=1)$ flow which divides French exporter's flow iterating the French firm over $j=2$ to 10 , until a non-missing tetrad is generated. If the tetrad is still missing, the procedure then goes to the Chinese exporter ranked $j=2$ and restarts iterating until Chinese exporter ranked $j=10$ is reached.

It is apparent in equation (9) that the identification of the effect of tariffs is possible over several dimensions: essentially across i) destination countries and ii) products, both interacted with variance across reference countries. In our baseline cross-section estimations, we investigate the various dimensions, by sequentially including product-reference or destination-reference fixed effects to the baseline specification. In the panel estimations reported as robustness checks in the appendix, we exploit variation of tariffs within products-destinations over time and across reference countries with product-destination, year and importing reference country fixed effects. There might be unobservable destination country characteristics, such as political factors or uncertainty on trading conditions, that can generate a correlated error-term structure, potentially biasing downwards the 
standard error of our variable of interest. Hence, standard errors are clustered at the destination level in the baseline specifications. ${ }^{9}$

Finally, one might be worried by the presence of unobserved bilateral trade costs that might be correlated with our measure of applied tariffs. Even though it is not clear that the correlation with those omitted trade costs should be systematically positive, we use, as a robustness check, a more inclusive measure of applied trade costs, the Ad Valorem Equivalent (AVE) tariffs from WITS and MAcMAp databases, described in the next section.

\section{Data}

- Trade: Our dataset combines Chinese and French firm-level exports for the year 2000. The French trade data comes from the French Customs, which provide annual export data at the product level for French firms. ${ }^{10}$ The customs data are available at the 8 -digit product level Combined Nomenclature ( $\mathrm{CN})$ and specify the country of destination of exports. The free on board (f.o.b) value of exports is reported in euros and we converted those to US dollars using the real exchange rate from Penn World Tables for 2000. The Chinese transaction data comes from the Chinese Customs Trade Statistics (CCTS) database which is compiled by the General Administration of Customs of China. This database includes monthly firm-level exports at the 8-digit HS product-level (also reported f.o.b) in US dollars. The data is collapsed to yearly frequency. The database also records the country of destination of exports. In both cases, export values are aggregated at the firm-product(hs6)-destination level in order to match with applied tariffs information that are available at the hs6-destination level. ${ }^{11}$

- Tariffs: Tariffs come from the WITS (World Bank) database. ${ }^{12}$ We rely on the ad valorem rate effectively applied at the hs6 level by each importer country to France and China. In our cross-section analysis performed for the year 2000 before the entry of China into the World Trade Organization (WTO), we exploit different sources of variation within hs6 products across importing countries on the tariff applied to France and China. The first variation naturally comes from the European Union (EU) importing countries that apply zero tariffs to trade with EU partners (like France) and a common external tariff to extra-EU countries (like China). The second source of variation in the year 2000 is that several non-EU countries applied the Most

\footnotetext{
${ }^{9}$ Since the level of clustering (destination country) is not nested within the level of fixed effects and the number of clusters is quite small with respect to the size of each cluster, we also implement the solution proposed by Wooldridge (2006). He recommends to run country-specific random effects on pair of firms demeaned data, with a robust covariance matrix estimation. This methodology is also used by Harrigan and Deng (2010) who encounter a similar problem. The results, available upon request, are robust under this specification.

${ }^{10}$ This database is quite exhaustive. Although reporting of firms by trade values below 250,000 euros (within the EU) or 1,000 euros (rest of the world) is not mandatory, there are in practice many observations below these thresholds.

${ }^{11}$ The hs6 classification changes over time. During our period of analysis it has only changed once in 2002 . To take into account this change in the classification of products, we have converted the HS-2002 into HS-1996 classification using WITS conversion tables.

${ }^{12}$ Information on tariffs is available at http://wits.worldbank.org/wits/
} 
Favored Nation tariff (MFN) to France, while the effective tariff applied to Chinese products was different (since China was not yet a member of WTO). We describe those countries and tariff levels below.

- Gravity controls: In all estimations, we include additional trade barriers variables that determine bilateral trade costs, such as distance, common (official) language, colony and common border (contiguity). The data come from the CEPII distance database. ${ }^{13}$ We use the populationweighted great circle distance between the set of largest cities in the two countries.

\subsection{Reference importer countries}

The use of a reference country, $k$ in equation (5), is crucial for a consistent identification of the trade elasticity. We choose reference importer countries with two criteria in mind. First, these countries should be those that are the main trade partners of France and China in the year 2000, since we want to minimize the number of zero trade flows in the denominator of the tetrad. The second criteria relies on the variation in the tariffs effectively applied by the importing country to France and China. Hence, among the main trade partners, we retain those countries for which the average difference between the effectively applied ad valorem tariffs to France and China is greater. These two criteria lead us to select the following set of 8 reference countries: Australia, Canada, Germany, Italy, Japan, New Zealand, Poland and the UK. Tables A.3 and A.4 in the appendix present, for each destination country, the count of products for which the difference in tariffs applied to France and China is positive, negative or zero, together with the average tariff gap.

For the sake of exposition, our descriptive analysis of reference countries relates only to the two main relevant trade partners of France and China in our sample. In the case of France, the main trade partner is Germany. The main trade partner of China is the US and the second one is Japan. Given that the US has applied the MFN tariff to China in several products before the entry of China in WTO, there is almost no variation in the difference in effectively applied ad valorem tariffs by the US to France and China in 2000. Hence, we use in the following descriptive statistics Germany and Japan as reference importer countries.

The difference in the effectively applied tariffs to France and China at the industry level by reference importer country (Germany and Japan) is presented in figure 1 (with precise numbers provided in the appendix, Table A.1). As can be noticed, there is a significant variation across 2-digit industries in the average percentage point difference in applied tariffs to both exporting countries in the year 2000. This variation is even more pronounced at the hs6 product level. Our empirical strategy will exploit this variation within hs6 products and across destination countries.

\footnotetext{
${ }^{13}$ This dataset is available at http://www.cepii.fr/anglaisgraph/bdd/distances.htm
} 
Figure 1 - Average percentage point difference between the applied tariff to France and China across industries by Germany and Japan (2000)

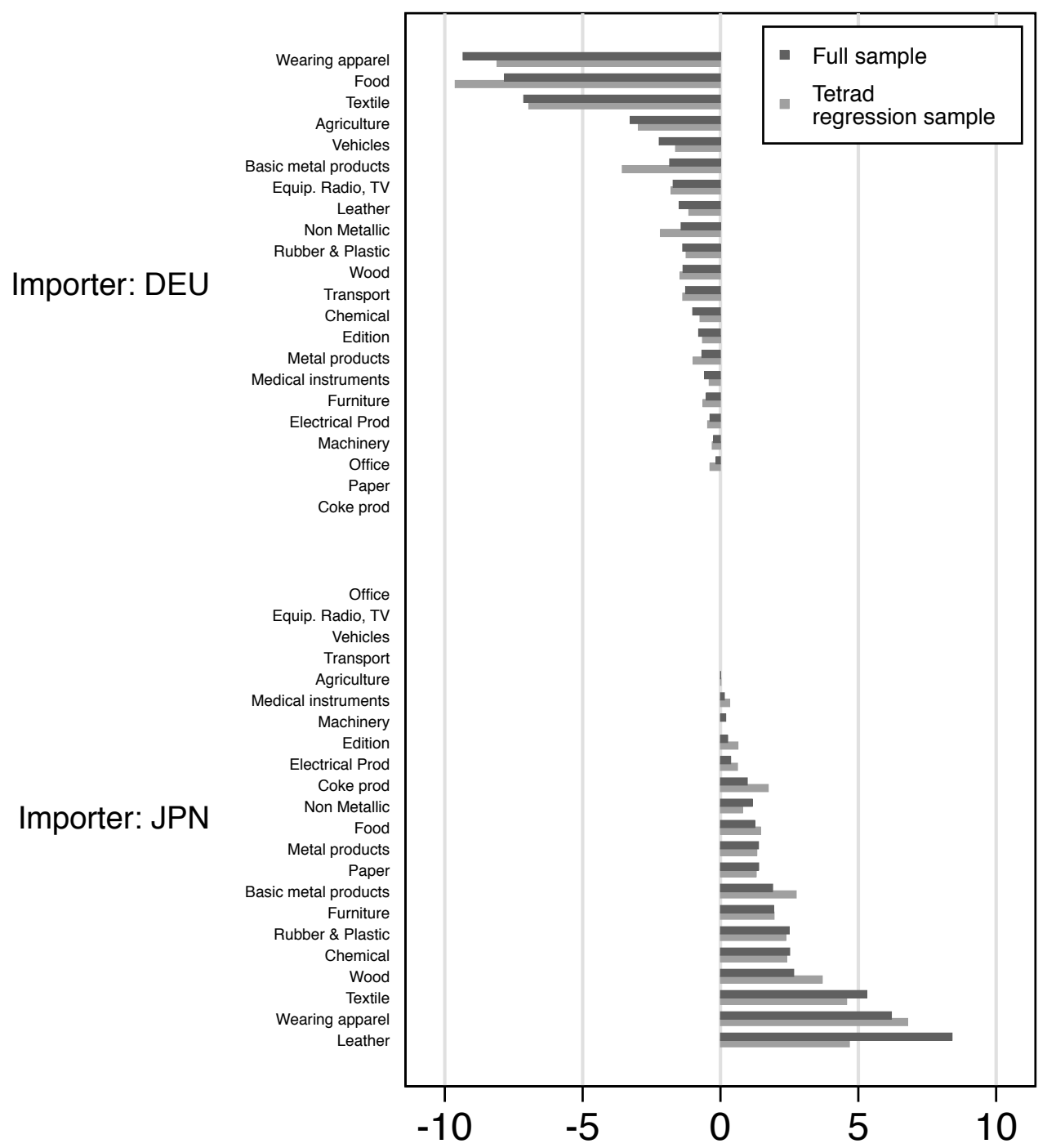

Source: Authors' calculation based on Tariff data from WITS (World Bank). 


\subsection{Estimating sample}

Our dependent variable is the log of a ratio of ratios of firm-level exports of firms with rank $j$ of product $p$ to destination $n$. The two ratios use the French/Chinese origin of the firm, and the reference country dimension $k$.

Firms are ranked according to their export value for each hs6 line and reference importer country. We first take the ratio of ratios of exports of the top 1 French and Chinese firms and then we complete the missing export values for hs6 product-destination pairs with lower ranked firms (top 2 to top 10). The final estimating sample is composed of 99,645 (37,396 for the top 1 exporting firm) product-destination-reference country observations in the year 2000.

The number of hs6 products and destination countries used in estimation is lower than the ones available in the original French and Chinese customs datasets since we need that the top 1 (to top 10) French exporting firm exports the same hs6 product that the top 1 (to top 10) Chinese exporting firm to at least the reference country as well as the destination country. The total number of hs6 products in the estimating sample is 2649. The same restriction applies to destination countries. We manage to keep 74 such destination countries.

Table A.2 in the appendix presents descriptive statistics of the main variables at the destination country level for the countries present in the estimating sample. It reports population and GDP for each destination country in 2000, as well as the ratios of total exports, average exports, total number of exporting firms, and distance between France and China. Only 12 countries in our estimating sample are closer to China than to France. In all of those, the number of Chinese exporters is larger than the number of French exporters, and the total value of Chinese exports largely exceeds the French one. On the other end of the spectrum, countries like Belgium and Switzerland witness much larger counts of exporters and total flows from France than from China, as expected.

\section{Estimates of the demand side parameter}

\subsection{Graphical illustration}

Before estimation, we turn to describing graphically the relationship between export flows and applied tariffs tetrads for different destination countries across products. In the interest of parsimony we focus again on the two main reference importer countries ( $k$ is Germany or Japan) and a restricted set of six destination countries ( $n$ is Australia, Brazil, USA, Canada, Poland or Thailand). We calculate for each hs6 product $p$ the tetradic terms for exports of French and Chinese firms ranked $j=1$ to 10 th as $\ln \widetilde{x}_{\{j, n, k\}}^{p}=\ln x_{n}^{p}\left(\alpha_{j, \mathrm{FR}}\right)-\ln x_{k}^{p}\left(\alpha_{j, \mathrm{FR}}\right)-\ln x_{n}^{p}\left(\alpha_{j, \mathrm{CN}}\right)+\ln x_{k}^{p}\left(\alpha_{j, \mathrm{CN}}\right)$ and the

tetradic term for applied tariffs at the same level as $\ln \left(\widetilde{1+t_{\{n, k\}}^{p}}\right)=\ln \left(1+t_{n \mathrm{FR}}^{p}\right)-\ln \left(1+t_{k \mathrm{FR}}^{p}\right)-$ $\ln \left(1+t_{n \mathrm{CN}}^{p}\right)+\ln \left(1+t_{k \mathrm{CN}}^{p}\right)$, 
Figure 2 report these tetrad terms to document the raw (and unconditional) evidence of the effect of tariffs on exported values by individual firms. The graphs also display the regression line and estimated coefficients of this simple regression of the logged export tetrad on the log of tariff tetrad for each of the six destination countries. Each point corresponds to a given hs6 product, and we highlight the cases where the export tetrad is calculated out of the largest $(j=1)$ French and Chinese exporters with a circle. The observations corresponding to Germany as a reference importer country are marked by a triangle, when the symbol is a square for Japan.

These estimations exploit the variation across products on tariffs applied by the destination country $n$ and reference importer country $k$ to China and France. In all cases, the estimated coefficient on tariff is negative and highly significant as shown by the slope of the line reported in each of each graphs. Those coefficients are quite large in absolute value, denoting a very steep response of consumers to differences in applied tariffs.

Figure 3 exposes a different dimension of identification, by looking at the impact of tariffs for specific products. We graph, following the logic of Figure 2 the tetrad of export value against the tetrad of tariffs for six individual products, which are the ones for which we maximize the number of observations in the dataset. Again (apart from the tools sector, where the relationship is not significant), all those sectors exhibit strong reaction to tariff differences across importing countries. A synthesis of this evidence for individual sectors can be found by averaging tetrads over a larger set of products. We do that in Figure 4 for the 184 products that have at least 30 destinations in common in our sample for French and Chinese exporters. The coefficient is again very large in absolute value and highly significant. The next section presents regression results with the full sample, both dimensions of identification, and the appropriate set of gravity control variables which will confirm this descriptive evidence and, as expected reduce the steepness of the estimated response.

\subsection{The intensive margin}

This section presents the estimates of the trade elasticity with respect to applied tariffs from equation (9) for all reference importer countries (Australia, Canada, Germany, Italy, Japan, New Zealand, Poland and the UK) pooled in the same specification. In all specifications standard errors are clustered by destination $\times$ reference country.

Estimations in Table 1 exploit the variations in tariffs applied to France and China across both products and destination countries. Columns (1) to (3) show the results using as dependent variable the ratio of the top 1 exporting French and Chinese firm. Columns (2) presents estimations on the sample of positive tetraded tariffs and column (3) controls for the tetradic terms of Regional Trade Agreements (RTA). Columns (4) to (6) of Table 1 present the estimations using as dependent variable the ratio of firm-level exports of the top 1 to the top 10 French and Chinese firms. These estimations yield coefficients for the applied tariffs $(1-\sigma)$ that range between -5.74 and -2.66 . Note that in both cases, the coefficients on applied tariffs are reduced when including the RTA, 
Figure 2 - Unconditional tetrad evidence: by importer
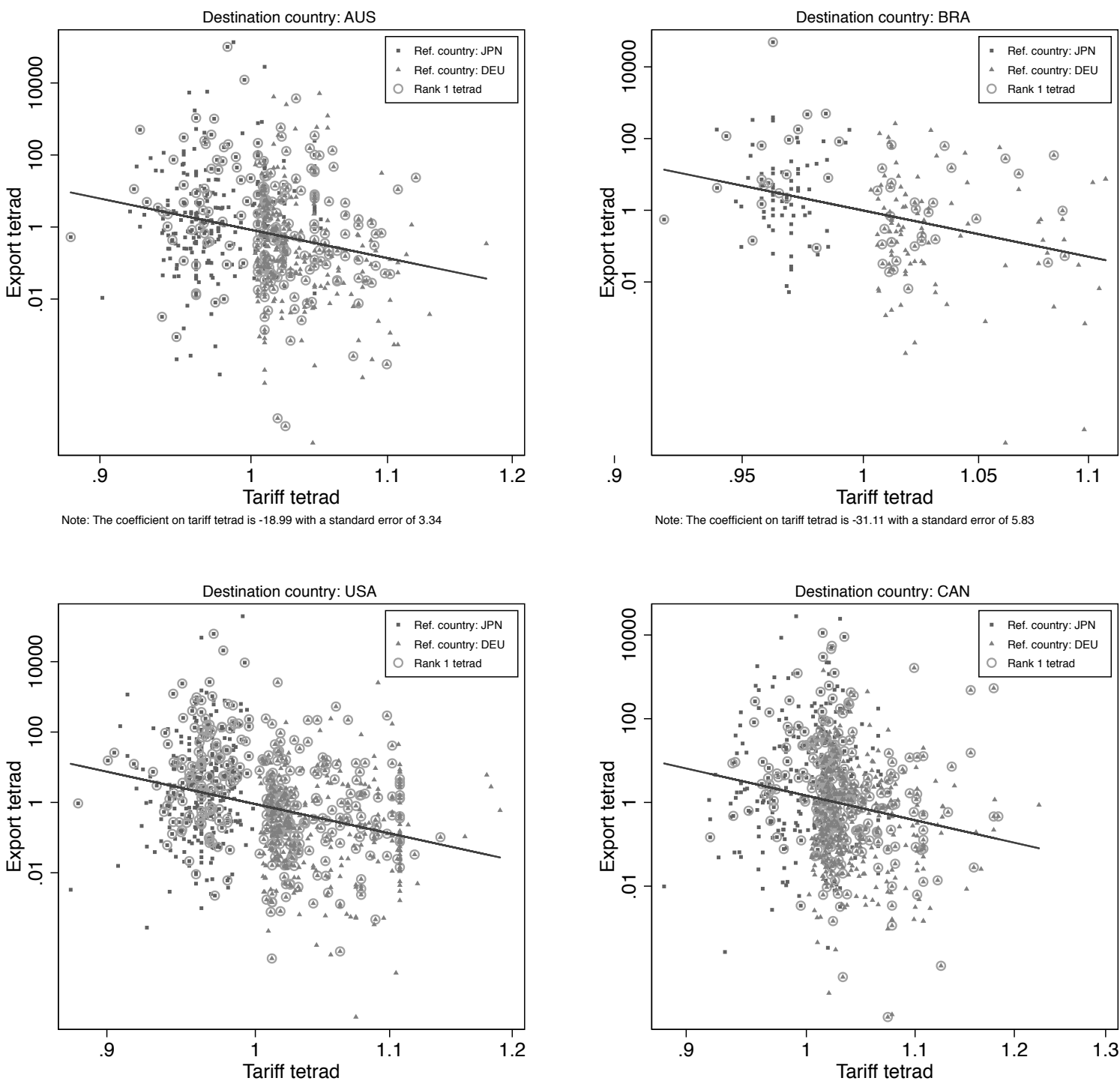

Note: The coefficient on tariff tetrad is -20.11 with a standard error of 2.21

Note: The coefficient on tariff tetrad is -14.19 with a standard error of 2.79
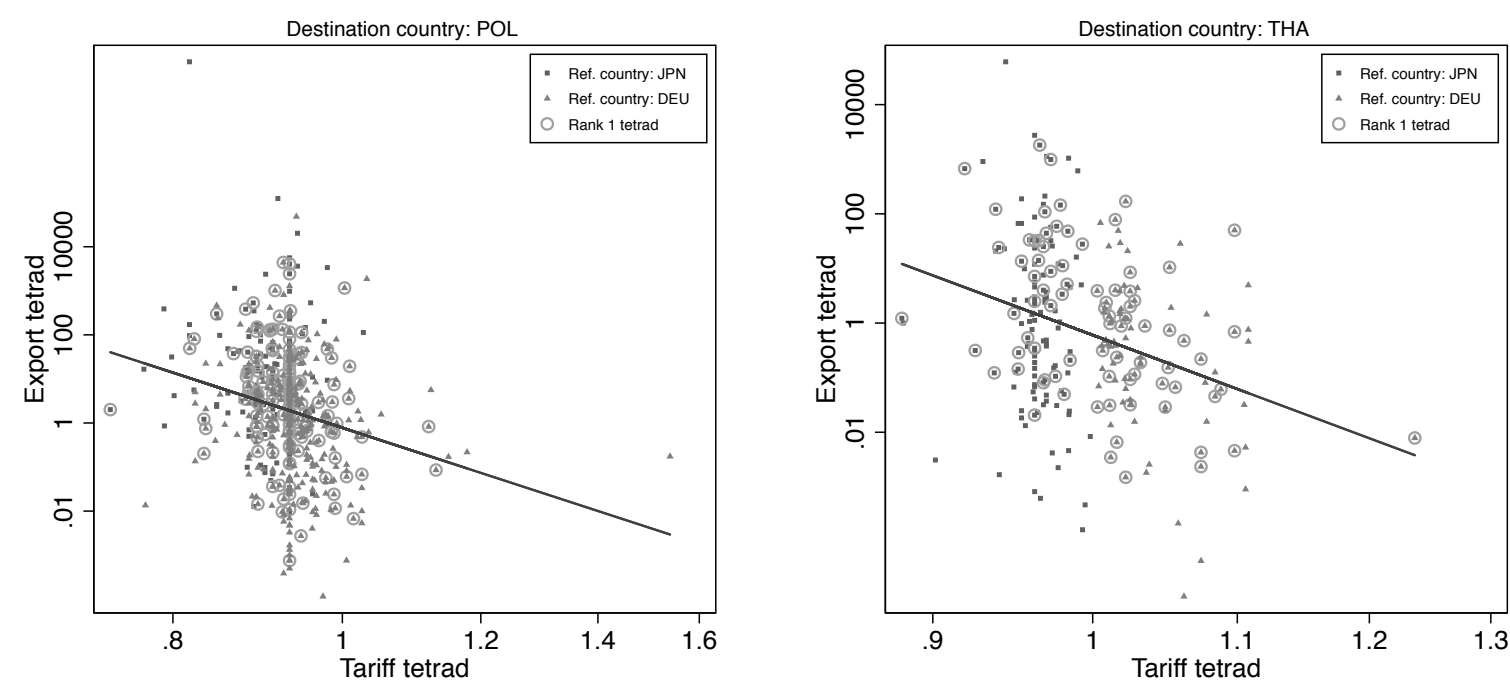

Note: The coefficient on tariff tetrad is -23.87 with a standard error of 4.91 
Figure 3 - Unconditional tetrad evidence: by product
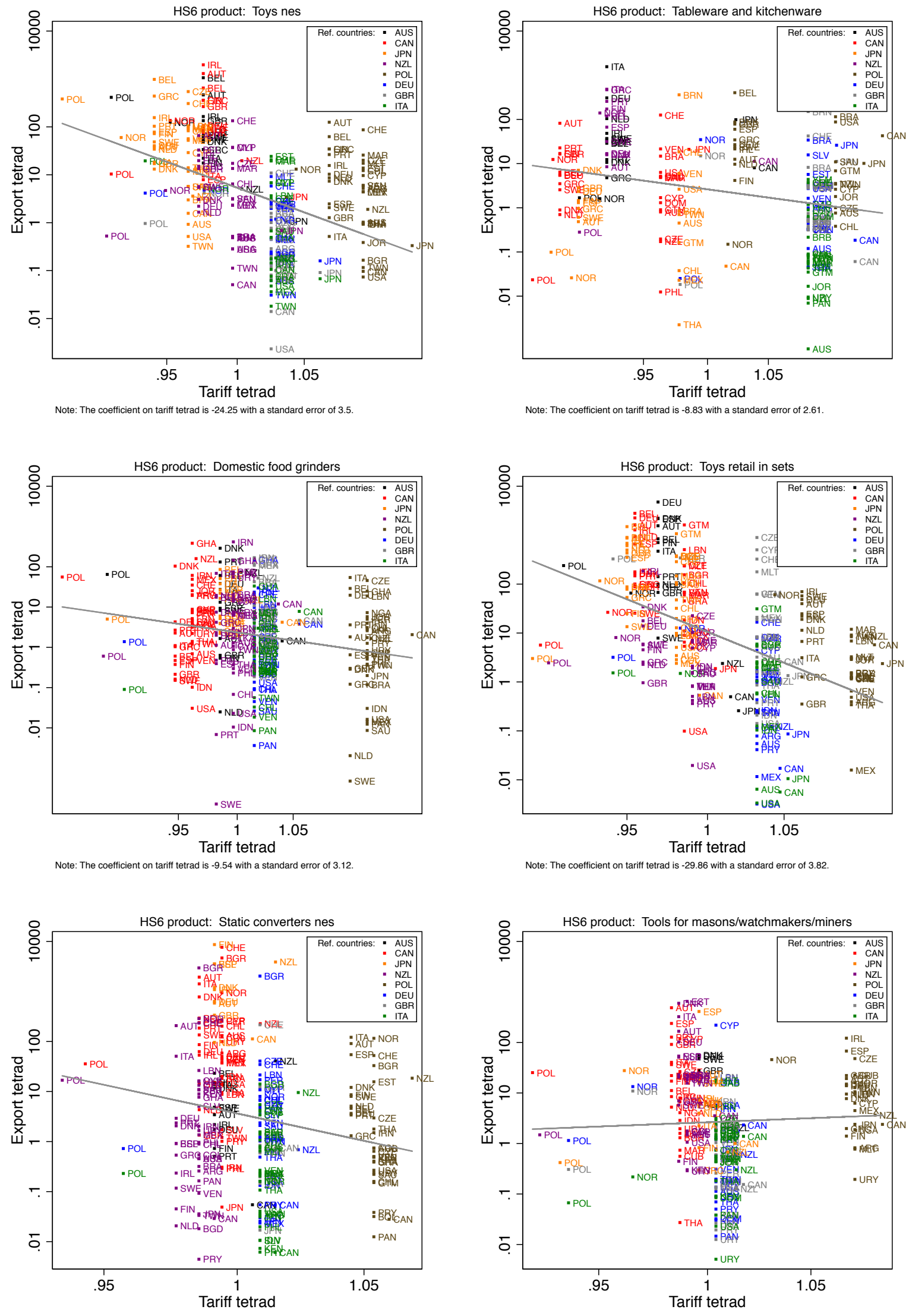

Note: The coefficient on tariff tetrad is 3.82 with a standard error of 5.83 
Figure 4 - Unconditional tetrad evidence: averaged over top products

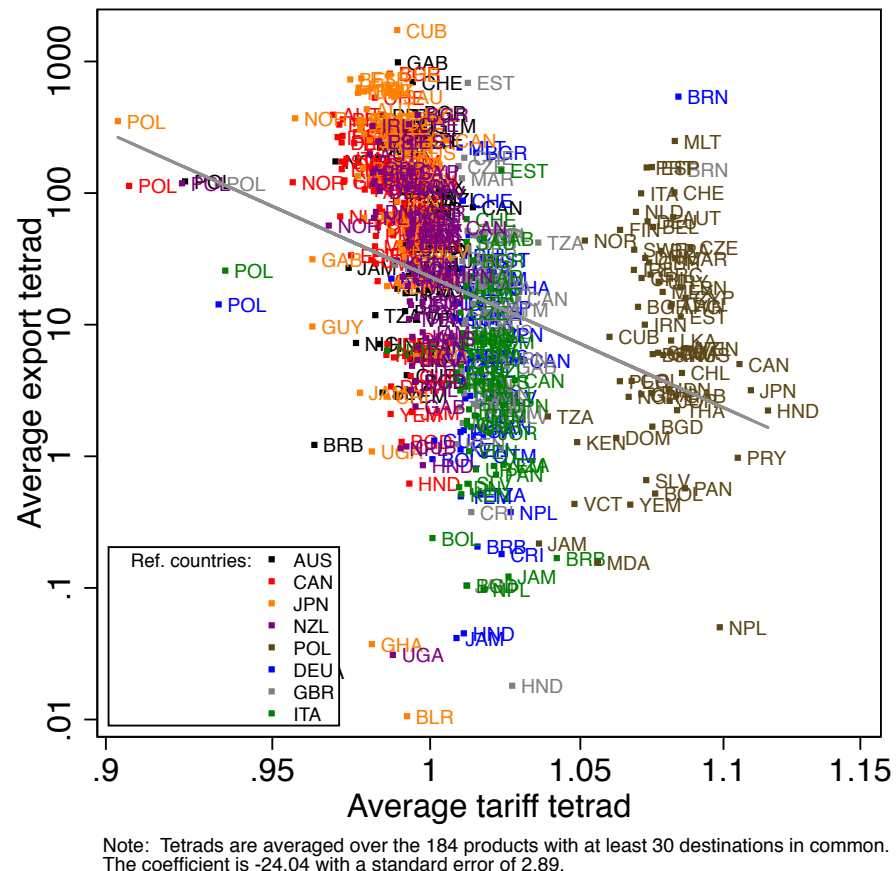
The coefficient is -24.04 with a standard error of 2.89 .

but that the tariff variable retains statistical significance, showing that the effect of tariffs is not restricted to the binary impact of going from positive to zero tariffs.

In Table 2 we focus on the variations in tariffs within product across destination countries. Thus, all specifications in this table include (hs6-product $\times$ reference country) fixed effects. The coefficients for the applied tariffs $(1-\sigma)$ range from -6 and -3.2 for the pair of the top 1 exporting French and Chinese firms (columns (1) to (3)). Columns (4) to (6) present the results using as dependent variable the pair of the top 1 to the top 10 firms. In this case, the applied tariffs vary from -4.1 to -1.65 . While RTA has a positive and significant effect, it again does not capture the whole effect of tariff variations across destination countries on export flows. Note also that distance and contiguity have the usual and expected signs and very high significance, while the presence of a colonial link and of a common language has a much more volatile influence.

As a more demanding specification, still identifying trade elasticity across destinations, we now restrict the sample to destination countries applying non-MFN tariffs to France and China. The sample of such countries contains Australia, Canada, Japan, New Zealand and Poland. ${ }^{14}$ Table 3 displays the results. Common language, contiguity and colony are excluded from the estimation since there is no enough variance in the non-MFN sample. Our non-MFN sample also does not

\footnotetext{
${ }^{14}$ To be on the conservative side, we exclude EU countries from the sample of non-MFN destinations since those share many other dimensions with France that might be correlated with the absence of tariffs (absence of Non-Tariff Barriers, free mobility of factors, etc.). Poland only enters the EU in 2004.
} 
Table 1 - Intensive margin elasticitiesin 2000.

\begin{tabular}{|c|c|c|c|c|c|c|}
\hline \multirow[t]{2}{*}{ Dependent variable: } & \multicolumn{3}{|c|}{$\begin{array}{c}\text { Top } 1 \\
\text { firm-level exports }\end{array}$} & \multicolumn{3}{|c|}{$\begin{array}{c}\text { Top } 1 \text { to } 10 \\
\text { firm-level exports }\end{array}$} \\
\hline & $(1)$ & $(2)$ & (3) & $(4)$ & $(5)$ & (6) \\
\hline \multirow[t]{2}{*}{ Applied Tariff } & $-5.74^{a}$ & $-4.83^{a}$ & $-3.83^{a}$ & $-4.54^{a}$ & $-4.65^{a}$ & $-2.66^{a}$ \\
\hline & $(0.76)$ & $(0.81)$ & $(0.71)$ & $(0.60)$ & $(0.61)$ & $(0.54)$ \\
\hline \multirow[t]{2}{*}{ Distance } & $-0.47^{a}$ & $-0.46^{a}$ & $-0.15^{a}$ & $-0.50^{a}$ & $-0.45^{a}$ & $-0.19^{a}$ \\
\hline & $(0.03)$ & $(0.03)$ & $(0.04)$ & $(0.02)$ & $(0.02)$ & $(0.03)$ \\
\hline \multirow[t]{2}{*}{ Contiguity } & $0.58^{a}$ & $0.75^{a}$ & $0.52^{a}$ & $0.60^{a}$ & $0.75^{a}$ & $0.54^{a}$ \\
\hline & $(0.08)$ & $(0.08)$ & $(0.07)$ & $(0.08)$ & $(0.07)$ & $(0.07)$ \\
\hline \multirow[t]{2}{*}{ Colony } & 0.27 & $0.63^{c}$ & -0.24 & -0.07 & 0.24 & $-0.61^{a}$ \\
\hline & $(0.29)$ & $(0.32)$ & $(0.29)$ & $(0.15)$ & $(0.18)$ & $(0.15)$ \\
\hline \multirow[t]{2}{*}{ Common language } & 0.10 & -0.09 & $0.39^{a}$ & 0.08 & -0.10 & $0.39^{a}$ \\
\hline & $(0.09)$ & $(0.09)$ & $(0.09)$ & $(0.08)$ & $(0.07)$ & $(0.07)$ \\
\hline \multirow[t]{2}{*}{ RTA } & & & $1.06^{a}$ & & & $1.07^{a}$ \\
\hline & & & $(0.12)$ & & & $(0.09)$ \\
\hline Observations & 37396 & 15477 & 37396 & 99645 & 41376 & 99645 \\
\hline$R^{2}$ & 0.137 & 0.189 & 0.143 & 0.146 & 0.181 & 0.153 \\
\hline rmse & 2.99 & 3.01 & 2.98 & 3.08 & 3.12 & 3.06 \\
\hline
\end{tabular}


Table 2 - Intensive margin elasticities in 2000 . Within-product estimations.

\begin{tabular}{|c|c|c|c|c|c|c|}
\hline \multirow[t]{2}{*}{ Dependent variable: } & \multicolumn{3}{|c|}{$\begin{array}{c}\text { Top } 1 \\
\text { firm-level exports }\end{array}$} & \multicolumn{3}{|c|}{$\begin{array}{c}\text { Top } 1 \text { to } 10 \\
\text { firm-level exports }\end{array}$} \\
\hline & $(1)$ & $(2)$ & (3) & $(4)$ & $(5)$ & $(6)$ \\
\hline Applied Tariff & $\begin{array}{l}-5.99^{a} \\
(0.79)\end{array}$ & $\begin{array}{l}-5.47^{a} \\
(1.07)\end{array}$ & $\begin{array}{l}-3.20^{a} \\
(0.79)\end{array}$ & $\begin{array}{l}-4.07^{a} \\
(0.72)\end{array}$ & $\begin{array}{l}-3.09^{a} \\
(0.75)\end{array}$ & $\begin{array}{l}-1.65^{b} \\
(0.68)\end{array}$ \\
\hline Distance & $\begin{array}{l}-0.54^{a} \\
(0.03)\end{array}$ & $\begin{array}{l}-0.49^{a} \\
(0.03)\end{array}$ & $\begin{array}{l}-0.21^{a} \\
(0.04)\end{array}$ & $\begin{array}{l}-0.59^{a} \\
(0.03)\end{array}$ & $\begin{array}{l}-0.55^{a} \\
(0.03)\end{array}$ & $\begin{array}{l}-0.29^{a} \\
(0.03)\end{array}$ \\
\hline Contiguity & $\begin{array}{l}0.93^{a} \\
(0.08)\end{array}$ & $\begin{array}{l}0.97^{a} \\
(0.09)\end{array}$ & $\begin{array}{l}0.84^{a} \\
(0.07)\end{array}$ & $\begin{array}{l}1.00^{a} \\
(0.07)\end{array}$ & $\begin{array}{l}0.94^{a} \\
(0.09)\end{array}$ & $\begin{array}{l}0.93^{a} \\
(0.07)\end{array}$ \\
\hline Colony & $\begin{array}{l}0.56^{a} \\
(0.21)\end{array}$ & $\begin{array}{l}0.48^{c} \\
(0.29)\end{array}$ & $\begin{array}{c}0.01 \\
(0.21)\end{array}$ & $\begin{array}{c}0.13 \\
(0.10)\end{array}$ & $\begin{array}{c}0.18 \\
(0.15)\end{array}$ & $\begin{array}{l}-0.34^{a} \\
(0.11)\end{array}$ \\
\hline Common language & $\begin{array}{l}-0.03 \\
(0.07)\end{array}$ & $\begin{array}{l}-0.00 \\
(0.08)\end{array}$ & $\begin{array}{l}0.25^{a} \\
(0.06)\end{array}$ & $\begin{array}{l}-0.07 \\
(0.06)\end{array}$ & $\begin{array}{l}-0.07 \\
(0.07)\end{array}$ & $\begin{array}{l}0.18^{a} \\
(0.06)\end{array}$ \\
\hline RTA & & & $\begin{array}{l}1.08^{a} \\
(0.11)\end{array}$ & & & $\begin{array}{l}0.94^{a} \\
(0.07)\end{array}$ \\
\hline Observations & 37396 & 15477 & 37396 & 99645 & 41376 & 99645 \\
\hline$R^{2}$ & 0.145 & 0.128 & 0.153 & 0.140 & 0.115 & 0.146 \\
\hline rmse & 2.14 & 1.99 & 2.13 & 2.42 & 2.26 & 2.41 \\
\hline
\end{tabular}

Notes: Standard errors are clustered by destination $\times$ reference country. All estimations include (hs6-product $\times$ reference country) fixed effects. Applied tariff is the tetradic term of the logarithm of applied tariff plus one. Columns (2) and (5) present estimations on the sample of positive tetraded tariffs. ${ }^{a},{ }^{b}$ and ${ }^{c}$ denote statistical significance levels of one, five and ten percent respectively. 
allow for including a RTA dummy. Estimations in columns (3) and (4) include fixed effect for each product $\times$ reference country. Columns (2) and (4) present estimations on the non-MFN sample of positive tetraded tariffs. In all cases, the coefficient of applied tariffs is negative and statistically significant with a magnitude from -5.47 to -3.24 . Hence, in spite of the large reduction in sample size, the results are very comparable to those obtained on the full sample of tariffs.

Table 3 - Intensive margin: non-MFN sample.

\begin{tabular}{lcccc}
\hline \multirow{2}{*}{ Dependent variable: } & \multicolumn{5}{c}{ Top 1 to 10 } \\
\hline & $(1)$ & $(2)$ & $(3)$ & $(4)$ \\
\hline \multirow{3}{*}{ Applied Tariff } & & & & \\
& $-3.87^{a}$ & $-5.36^{a}$ & $-3.24^{a}$ & $-5.47^{a}$ \\
& $(1.09)$ & $(1.14)$ & $(1.09)$ & $(1.03)$ \\
Distance & & & & \\
& $-0.50^{a}$ & $-0.41^{a}$ & $-0.45^{a}$ & $-0.36^{a}$ \\
Observations & $(0.03)$ & $(0.03)$ & $(0.05)$ & $(0.05)$ \\
$R^{2}$ & 12992 & 9421 & 12992 & 9421 \\
rmse & 0.102 & 0.094 & 0.058 & 0.062 \\
\hline \hline
\end{tabular}

Notes: Standard errors are clustered by destination $\times$ reference country. Columns (3) and (4) include fixed effects at the (hs6 product $\times$ reference country) level. Applied tariff is the tetradic term of the logarithm of applied tariff plus one. Columns (2) and (4) present estimations on the sample of positive tetraded tariffs. ${ }^{a},{ }^{b}$ and ${ }^{c}$ denote statistical significance levels of one, five and ten percent respectively.

In Appendix A.8.2. we present a number of alternative specifications of the intensive margin estimates. First, we exploit variations in applied tariffs within destination countries across hs6products as an alternative dimension of identification. By contrast, our baseline estimations exploit variation of applied tariffs within hs6 products across destination countries and exporters (firms located in France and China). The results are robust to this new source of identification. Second, we complement the cross-sectional analysis of our baseline specifications-undertaken for the year 2000 , i.e. before entry of China into WTO. We consider two additional cross-sectional samples, one after China entry into WTO (2001), the other for the final year of our sample (2006). Here again the results are qualitatively robust, although the coefficients on tariffs are lower since the difference of tariffs applied to France and China by destination countries is reduced after 2001. Third, we consider panel estimations over the 2000-2006 period. This analysis exploits the variations in tariffs within product-destination over time and across reference countries. The panel dimension allows for the inclusion of three sets of fixed effects: Product-destination, year and reference country. The coefficients of the intensive margin elasticity are close to the findings from the baseline crosssection estimations in 2000 , and they range from -5.26 to -1.80 . 
Finally we address in the Appendix an econometric concern that is linked to endogenous selection into export markets. To understand the potential selection bias associated with estimating the trade elasticity it is useful to recall that selection is due to the presence of a fixed export cost that makes some firms unprofitable in some markets. Therefore higher tariff countries will be associated with firms having drawn a more favorable demand shock thus biasing downwards our estimate of the trade elasticity. Our approach of tetrads that focuses on highly ranked exporters for each hs6market combination should however not be too sensitive to that issue, since those are firms that presumably have such a large productivity that their idiosyncratic destination shock is of second order. ${ }^{15}$ In order to verify that intuition, we follow Eaton and Kortum (2001), applied to firm-level data by Crozet et al. (2012), yielding a generalized structural tobit. This method (EK tobit) keeps all individual exports to all possible destination markets (including zeroes). Strikingly, the EK tobit estimates are very comparable to our baseline tetrad estimates, giving us further confidence in an order of magnitude of the firm-level trade elasticity around located between -4 and -6 .

\section{Aggregate trade elasticities}

The objective of this section is to provide a theory-consistent methodology for inferring, from firm-level data, the aggregate elasticity of trade with respect to trade costs. Given this objective, our methodology requires to account for the full distribution of firm-level productivity, i.e. we now need to add supply-side determinants of the trade elasticity to the demand-side aspects developed in previous sections (see equation 1). Following Head et al. (2014), we consider two alternative distributions - Pareto, as is standard in the literature, and log-normal —and we provide two sets of estimates, one for each considered distribution. ${ }^{16}$ The Pareto assumption has this unique feature that the aggregate elasticity is constant, and depends only on the dispersion parameter of the Pareto, that is on supply only, a result first emphasized in Chaney (2008). Without Pareto, things are notably more complex, as the trade elasticity varies across country pairs. In addition, calculating this elasticity requires knowledge of the bilateral cost cutoff under which the considered country is unprofitable.

To calculate this bilateral cutoff, we combine our estimate of the demand side parameter $\hat{\sigma}$ with a dyadic micro-level observable, the mean-to-min ratio, that corresponds to the ratio of average over minimum sales of firms for a given country pair. In the model, this ratio measures the endogenous dispersion of cross-firm performance on a market, and more precisely the relative performance of entrants in this market following a change in our variable of interest: variable trade costs.

Under Pareto, the mean-to-min ratio, for a given origin, should be constant and independent of

\footnotetext{
${ }^{15}$ It might be the case that those top firms exhibit a different trade elasticity than the rest of the firms' population. The finding by Berman et al. (2012) that the reaction to exchange rate changes declines with productivity suggests that the estimates in this paper could be considered as a lower bound.

${ }^{16}$ Unless otherwise specified, Pareto is understood here as the un-truncated version used by most of the literature. See Helpman et al. (2008) and Melitz and Redding (2015) for results with the truncated version, where the trade elasticity recovers a bilateral dimension.
} 
the size of the destination market. This pattern of scale-invariance is not observed in the data where we see that mean-to-min ratios increase massively in large markets-a feature consistent with a log-normal distribution of firm-level productivity. In the last step of the section we compare our micro-based predicted elasticities to those estimated with a gravity-like approach based on macro-data.

\subsection{Quantifying aggregate trade elasticities from firm-level data: Theory}

In order to obtain the theoretical predictions on aggregate trade elasticities, we start by summing, for each country pair, the sales equation (2) across all active firms:

$$
X_{n i}=V_{n i} \times\left(\frac{\sigma}{\sigma-1}\right)^{1-\sigma}\left(w_{i} \tau_{n i}\right)^{1-\sigma} A_{n} M_{i}^{e},
$$

where $M_{i}^{e}$ is the mass of entrant firms and $V_{n i}$ denotes a cost-performance index of exporters located in country $i$ and selling in $n$. This index is characterized by

$$
V_{n i} \equiv \int_{0}^{a_{n i}^{*}} a^{1-\sigma} g(a) d a,
$$

where $a \equiv \alpha \times b(\alpha)$ corresponds to the unitary labor requirement rescaled by the firm-destination shock. In equation (11), $g($.$) denotes the pdf of the rescaled unitary labor requirement and a_{n i}^{*}$ is the rescaled labor requirement of the cutoff firm. The solution for the cutoff is the cost satisfying the zero profit condition, i.e., $x_{n i}\left(a_{n i}^{*}\right)=\sigma w_{i} f_{n i}$. Using (2), this cutoff is characterized by

$$
a_{n i}^{*}=\frac{1}{\tau_{n i} f_{n i}^{1 /(\sigma-1)}}\left(\frac{1}{w_{i}}\right)^{\sigma /(\sigma-1)}\left(\frac{A_{n}}{\sigma}\right)^{1 /(\sigma-1)} .
$$

We are interested in the (partial) elasticity of aggregate trade value with-respect to variable trade costs, $\tau_{n i}$. Partial means here holding constant origin-specific and destination-specific terms (income and price indices) as in Arkolakis et al. (2012) and Melitz and Redding (2015). In practical terms, the use of importer and exporter fixed effects in gravity regressions (the main source of estimates of the aggregate elasticity) holds $w_{i}, M_{i}$ and $A_{n}$ constant, so that, using (10), we have ${ }^{17}$

$$
\varepsilon_{n i} \equiv \frac{d \ln X_{n i}}{d \ln \tau_{n i}}=1-\sigma-\gamma_{n i}
$$

where $\gamma_{n i}$ is a very useful term, studied by Arkolakis et al. (2012), describing how $V_{n i}$ varies with an increase in the cutoff cost $a_{n i}^{*}$, that is an easier access of market $n$ for firms in $i$ :

$$
\gamma_{n i} \equiv \frac{d \ln V_{n i}}{d \ln a_{n i}^{*}}=\frac{a_{n i}^{* 2-\sigma} g\left(a_{n i}^{*}\right)}{V_{n i}} .
$$

\footnotetext{
${ }^{17}$ While this is literally true under Pareto because $w_{i}, M_{i}$ and $A_{n}$ enter $a_{n i}^{*}$ multiplicatively, deviating from Pareto adds a potentially complex interaction term through a non-linear in logs effect of monadic terms on the dyadic cutoff. We expect this effect to be of second order.
} 
Equation (13) means that the aggregate trade elasticity may not be constant across country pairs because of the $\gamma_{n i}$ term. In order to evaluate those bilateral trade elasticities, combining (14) with (11) reveals that we need to know the value of bilateral cutoffs $a^{*}$. In order to obtain those, we define the following function

$$
\mathcal{H}\left(a^{*}\right) \equiv \frac{1}{a^{* 1-\sigma}} \int_{0}^{a^{*}} a^{1-\sigma} \frac{g(a)}{G\left(a^{*}\right)} d a,
$$

a monotonic, invertible function which has a straightforward economic interpretation in this model. It is the ratio of average over minimum performance (measured as $a^{* 1-\sigma}$ ) of firms located in $i$ and exporting to $n$. Using equations (2) and (10), this ratio also corresponds to the observed mean-to-min ratio of sales:

$$
\frac{\bar{x}_{n i}}{x_{n i}\left(a_{n i}^{*}\right)}=\mathcal{H}\left(a_{n i}^{*}\right)
$$

For our two origin countries (France and China), we observe the ratio of average to minimum trade flows for each destination country $n$. Using equation (16), one can calibrate $\hat{a}_{n \mathrm{FR}}^{*}$ and $\hat{a}_{n \mathrm{CN}}^{*}$, the estimated value of the export cutoff for French and Chinese firms exporting to $n$ as a function of the mean-to-min ratio of French and Chinese sales on each destination market $n$

$$
\hat{a}_{n \mathrm{FR}}^{*}=\mathcal{H}^{-1}\left(\frac{\bar{x}_{n \mathrm{FR}}}{x_{n \mathrm{FR}}^{\mathrm{MIN}}}\right), \quad \text { and } \quad \hat{a}_{n \mathrm{CN}}^{*}=\mathcal{H}^{-1}\left(\frac{\bar{x}_{n \mathrm{CN}}}{x_{n \mathrm{CN}}^{\mathrm{MIN}}}\right) .
$$

Equipped with the dyadic cutoffs we combine (13), (14) and (11) to obtain the aggregate trade elasticities

$$
\varepsilon_{n \mathrm{FR}}=1-\hat{\sigma}-\frac{x_{n \mathrm{FR}}^{\mathrm{MIN}}}{\bar{x}_{n, \mathrm{FR}}} \times \frac{\hat{a}_{n \mathrm{FR}}^{*} g\left(\hat{a}_{n \mathrm{FR}}^{*}\right)}{G\left(\hat{a}_{n \mathrm{FR}}^{*}\right)}, \quad \text { and } \quad \varepsilon_{n \mathrm{CN}}=1-\hat{\sigma}-\frac{x_{n \mathrm{MNN}}^{\mathrm{MIN}}}{\bar{x}_{n \mathrm{CN}}} \times \frac{\hat{a}_{n \mathrm{CN}}^{*} g\left(\hat{a}_{n \mathrm{CN}}^{*}\right)}{G\left(\hat{a}_{n \mathrm{CN}}^{*}\right)},
$$

where $\hat{\sigma}$ is our estimate of the intensive margin (the demand-side parameter) from previous sections. Our inference procedure is characterized by equations (17), and (18). We can also calculate two other trade margins: the elasticity of the number of active exporters $N_{n i}$ (the so-called extensive margin) and the elasticity of average shipments $\bar{x}_{n i}$. The number of active firms is closely related to the cutoff since $N_{n i}=M_{i}^{e} \times G\left(a_{n i}^{*}\right)$, where $M_{i}^{e}$ represents the mass of entrants (also absorbed by exporter fixed effects in gravity regressions). Differentiating the previous relationship and using (18) we can estimate the dyadic extensive margin of trade

$$
\frac{d \ln N_{n \mathrm{FR}}}{d \ln \tau_{n \mathrm{FR}}}=-\frac{\hat{a}_{n \mathrm{FR}}^{*} g\left(\hat{a}_{n \mathrm{FR}}^{*}\right)}{G\left(\hat{a}_{n \mathrm{FR}}^{*}\right)}, \quad \text { and } \quad \frac{d \ln N_{n \mathrm{CN}}}{d \ln \tau_{n \mathrm{CN}}}=-\frac{\hat{a}_{n \mathrm{CN}}^{*} g\left(\hat{a}_{n \mathrm{CN}}^{*}\right)}{G\left(\hat{a}_{n \mathrm{CN}}^{*}\right)},
$$

From the accounting identity $X_{n i} \equiv N_{n i} \times \bar{X}_{n i}$, we obtain the (partial) elasticity of average shipments to trade simply as the difference between the estimated aggregate elasticities, (18) and the estimated extensive margins, (19).

$$
\frac{d \ln \bar{x}_{n \mathrm{FR}}}{d \ln \tau_{n \mathrm{FR}}}=\varepsilon_{n \mathrm{FR}}-\frac{d \ln N_{n \mathrm{FR}}}{d \ln \tau_{n \mathrm{FR}}} \quad \text { and } \quad \frac{d \ln \bar{x}_{n \mathrm{CN}}}{d \ln \tau_{n \mathrm{CN}}}=\varepsilon_{n \mathrm{CN}}-\frac{d \ln N_{n \mathrm{CN}}}{d \ln \tau_{n \mathrm{CN}}}
$$


For the sake of interpreting the role of the mean-to-min, we combine (18) and (19) to obtain a relationship linking the aggregate elasticities to the (intensive and extensive) margins and to the mean-to-min ratio. Taking France as an origin country for instance, we obtain:

$$
\varepsilon_{n \mathrm{FR}}=\underbrace{1-\hat{\sigma}}_{\text {intensive margin }}+\underbrace{\frac{1}{\bar{x}_{n \mathrm{FR}} / x_{n \mathrm{MIN}}^{\mathrm{MIN}}}}_{\text {min-to-mean }} \times \underbrace{\frac{d \ln N_{n \mathrm{FR}}}{d \ln \tau_{n \mathrm{FR}}}}_{\text {extensive margin }},
$$

which is equation (1) presented in the introduction. This decomposition shows that the aggregate trade elasticity is the sum of the intensive margin and of the (weighted) extensive margin. The weight on the extensive margin depends only on the mean-to-min ratio, an observable measuring the dispersion of relative firm performance. Intuitively, the weight of the extensive margin should be decreasing when the market gets easier. Indeed easy markets have larger rates of entry, $G\left(a^{*}\right)$, and therefore increasing presence of weaker firms which augments dispersion measured as $\mathcal{H}\left(a_{n i}^{*}\right)$. The marginal entrant in an easy market will therefore have less of an influence on aggregate exports, a smaller impact of the extensive margin. In the limit, the weight of the extensive margin becomes negligible and the whole of the aggregate elasticity is due to the intensive margin / demand parameter. In the Pareto case however this mechanism is not operational since $\mathcal{H}\left(a_{n i}^{*}\right)$ and therefore the weight of the extensive margin is constant. We now turn to implementing our method with Pareto as opposed to an alternative distribution yielding non-constant dispersion of sales across destinations.

\subsection{Quantifying aggregate trade elasticities from firm-level data: Results}

A crucial step for our quantification procedure consists in specifying the distribution of rescaled labor requirement, $G(a)$, which is necessary to inverse the $\mathcal{H}$ function, reveal the bilateral cutoffs and therefore obtain the bilateral trade elasticities. The literature has almost exclusively used the Pareto. Head et al. (2014) show that a credible alternative, which seems favored by firmlevel export data, is the log-normal distribution. Pareto-distributed rescaled productivity $\varphi \equiv 1 / a$ translates into a power law CDF for $a$, with shape parameter $\theta$. A log-normal distribution of $a$ retains the log-normality of productivity (with location parameter $\mu$ and dispersion parameter $\nu$ ) but with a change in the log-mean parameter from $\mu$ to $-\mu$. The CDFs for a are therefore given by

$$
G^{\mathrm{P}}(a)=\left(\frac{a}{\bar{a}}\right)^{\theta}, \quad \text { and } \quad G^{\mathrm{LN}}(a)=\Phi\left(\frac{\ln a+\mu}{\nu}\right),
$$

where we use $\Phi$ to denote the CDF of the standard normal. Simple calculations using (22) in (15), and detailed in Appendix 9:, show that the resulting formulas for $\mathcal{H}$ are

$$
\mathcal{H}^{\mathrm{P}}\left(a_{n i}^{*}\right)=\frac{\theta}{\theta-\sigma+1}, \quad \text { and } \quad \mathcal{H}^{\mathrm{LN}}\left(a_{n i}^{*}\right)=\frac{h\left[\left(\ln a_{n i}^{*}+\mu\right) / \nu\right]}{h\left[\left(\ln a_{n i}^{*}+\mu\right) / \nu+(\sigma-1) \nu\right]},
$$

where $h(x) \equiv \phi(x) / \Phi(x)$, the ratio of the PDF to the CDF of the standard normal. 
The left panel of Figure 5 depicts the theoretical behavior of the dyadic mean-to-min ratio (the empirical counterpart of $\mathcal{H}$ ) as a function of the probability of serving the destination market $G\left(a_{n i}^{*}\right)$ for all possible values of $a_{n i}^{*}$. Calculating those $\mathcal{H}^{\mathrm{P}}\left(a_{n i}^{*}\right)$ and $\mathcal{H}^{\mathrm{LN}}\left(a_{n i}^{*}\right)$ requires knowledge of underlying key supply-side distribution parameters $\theta$ and $\nu$. For those, we use estimates from the Quantile-Quantile (QQ) regressions in Head et al. (2014). This method, based on a regression of empirical against theoretical quantiles of log sales, is applied on the same samples of exporters (Chinese and French) as here, and requires an estimate of the CES. We choose $\hat{\sigma}=5$, which corresponds to a central value in our findings on the intensive margin above (where $1-\hat{\sigma} \simeq-4$ ). Under Pareto heterogeneity, the mean-to-min is constant but this property of scale invariance is specific to the Pareto: Indeed it is increasing in $G\left(a_{n i}^{*}\right)$ under log-normal.

Figure 5 - Theoretical and Empirical Mean-to-Min ratios

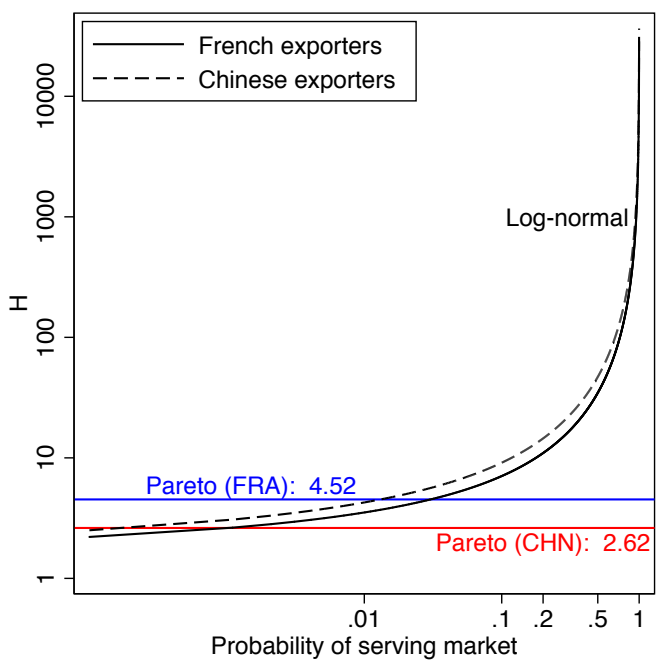

(a) theory

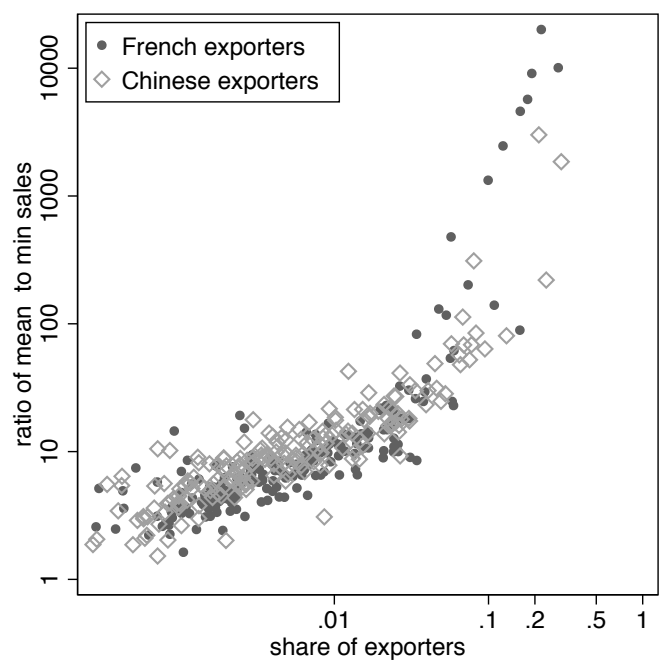

(b) data

Panel (b) of figure 5 depicts the empirical application of the $\mathcal{H}$ value for French and Chinese exporters in 2000 for all countries in the world. On the $\mathrm{x}$-axis is the share of exporters serving each of those markets. ${ }^{18}$ Immediately apparent is the non-constant nature of the mean-to-min ratio in the data, contradicting the Pareto prediction. This finding is very robust when considering (unreported) alternatives to the minimum sales (which might be noisy if only because of statistical threshold effects) for the denominator of $\mathcal{H}$, that is different quantiles of the export distribution.

Figure 6 turns to the predicted trade elasticities. Using functional forms from (22) into (14), the formulas for $\gamma_{n i}^{\mathrm{P}}$ and $\gamma_{n i}^{\mathrm{LN}}$, shown in the appendix, can be used to write the two aggregate elasticities:

\footnotetext{
${ }^{18}$ While this is not exactly the empirical counterpart of $G\left(a_{n i}^{*}\right)$, the x-axis of panel (a), those two shares differ by a multiplicative constant, leaving the shape of the (logged) relationship unchanged.
} 


$$
\varepsilon_{n i}^{\mathrm{P}}=-\theta, \quad \text { and } \quad \varepsilon_{n i}^{\mathrm{LN}}=1-\sigma-\frac{1}{\nu} h\left(\frac{\ln a_{n i}^{*}+\mu}{\nu}+(\sigma-1) \nu\right) .
$$

Panel (a) of figure 6 shows those elasticities calculated for each destination country for both Chinese and French exporters using the cutoff equations revealed from empirical values of $\mathcal{H}$ and using equation (24). Again, the Pareto case has a constant prediction (one for each exporter), while log normal predicts a trade elasticity that is declining (in absolute value) with easiness of the market. Panel (b) takes those predicted aggregate trade elasticities and plots them against actual physical distance. The two axes are taken as ratios of France over China, in order to eliminate destination specific factors $\left(A_{n}\right)$ in those elasticities. Distance is the simplest determinant of $\tau_{n i}$ and acts exactly as expected: more difficult (distant) markets exhibit larger predicted trade elasticities (which empirically corresponds to smaller mean-to-min sales ratios). The predicted elasticity on the extensive margin is also rising with market toughness in the theory (relative distance in the data) as shown in figure 7 . The inverse relationship is true for average exports. When a market is very easy and most exporters make it there, the extensive margin goes to zero, and the response of average exports goes to the value of the intensive margin (the firm-level response), $1-\sigma$, as shown in panel (a) of figure 8 . While this should intuitively be true in general, Pareto does not allow for this change in elasticities across markets, since the response of average exports should be uniformly 0 , while the total response is entirely due to the (constant) extensive margin. In Table 4, we compute the average value and standard deviation of bilateral trade elasticities calculated using log-normal, and presented in the preceding figures. The first column presents the statistics for the French exporters' sample, the second one is the Chinese exporters' case, and the last column averages those.

Figure 6 - Predicted trade elasticities: $\varepsilon_{n \mathrm{FR}}$ and $\varepsilon_{n \mathrm{CN}}$

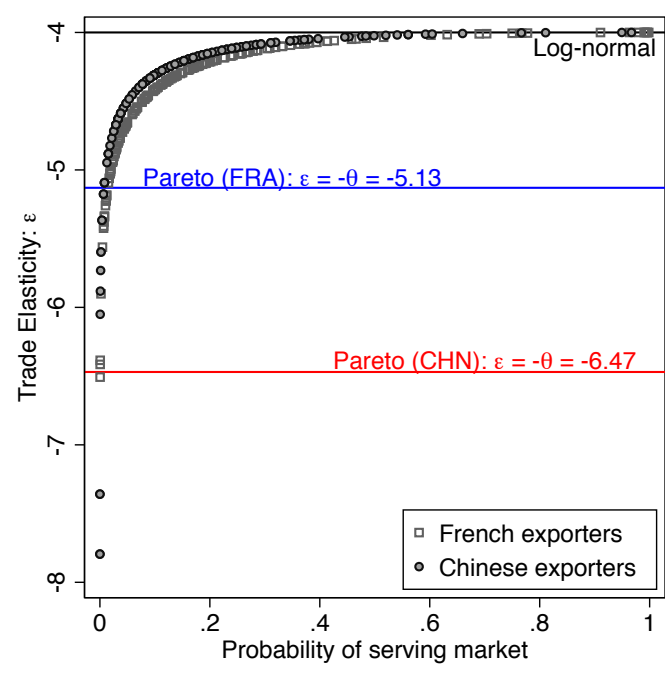

(a) theory

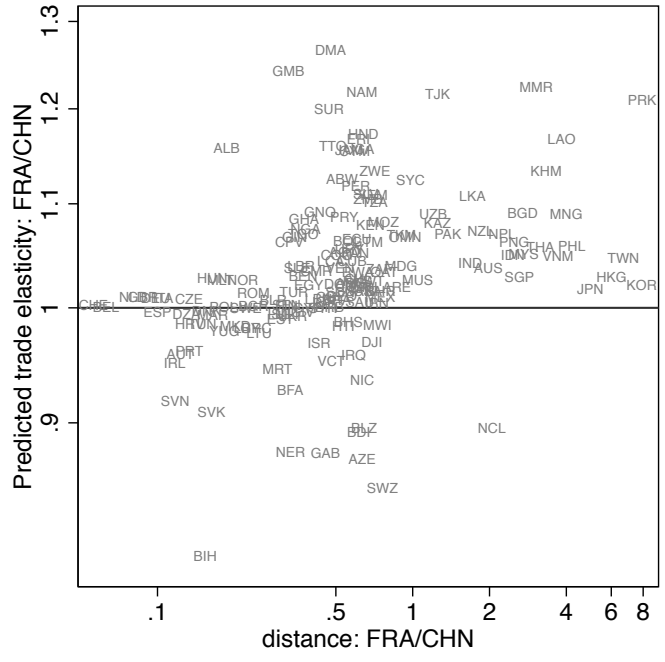

(b) predicted elas. vs distance 
Figure 7 - Predicted elasticities: extensive margin

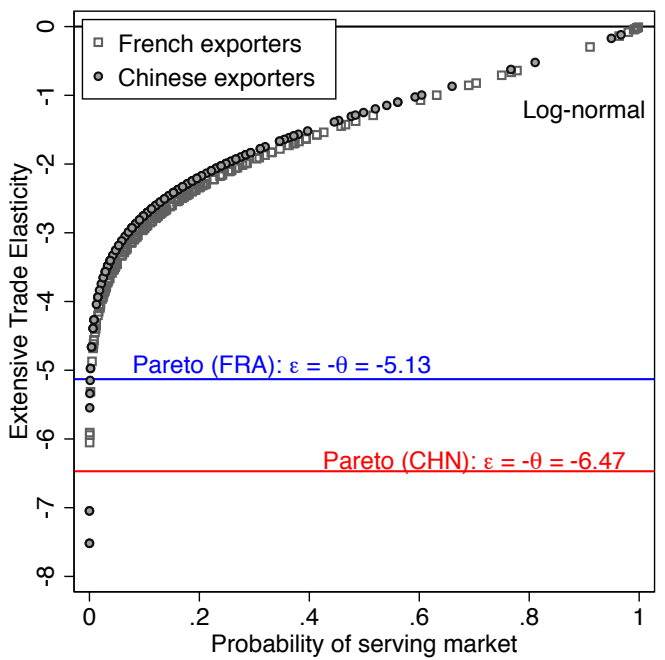

(a) theory

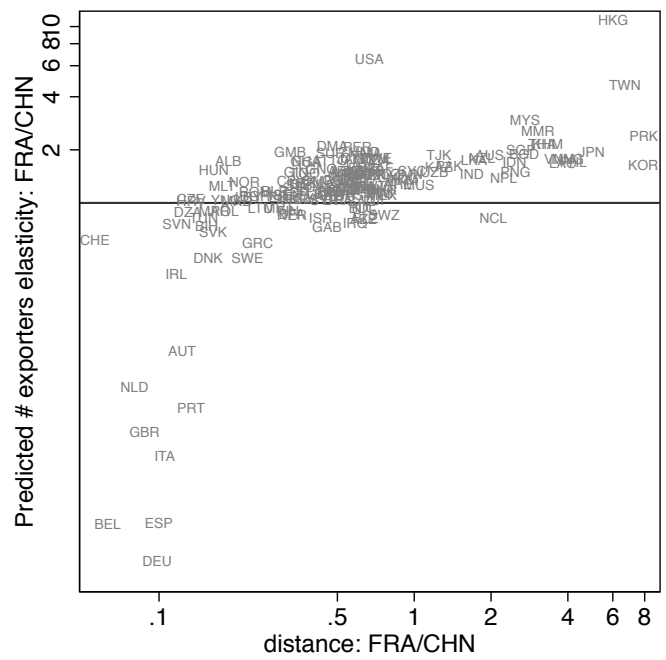

(b) predicted elas. vs distance

Figure 8 - Predicted elasticities: average exports

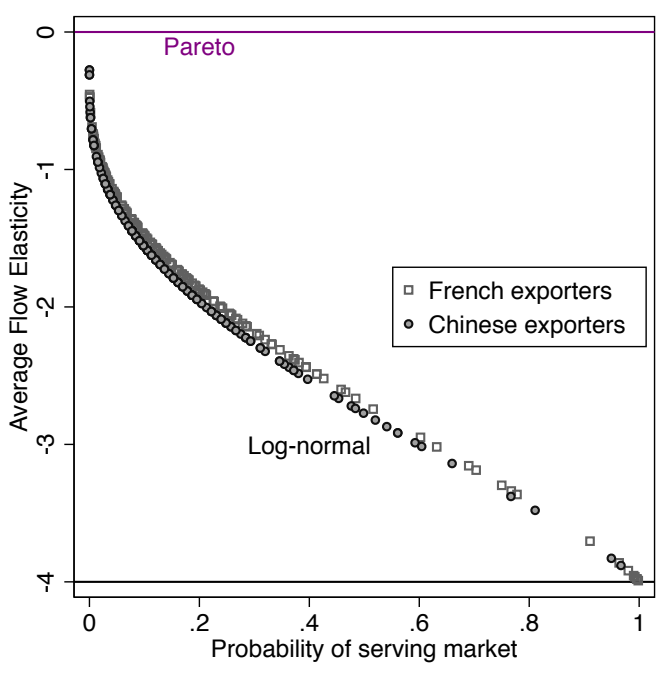

(a) theory

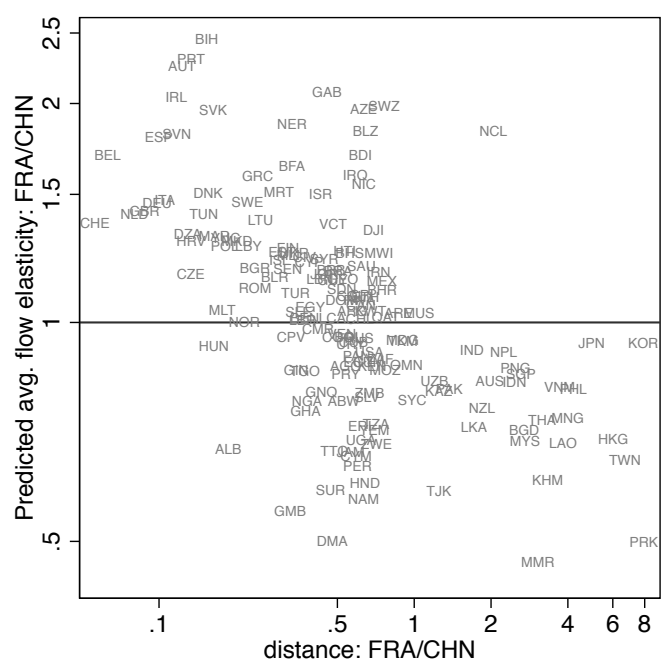

(b) predicted elas. vs distance

Figure 9 groups our bilateral trade elasticities $\left(\varepsilon_{n i}\right)$ into ten bins of export shares for both France and China in a way similar to empirical evidence by Novy (2013), which reports that the aggregate trade cost elasticity decreases with bilateral trade intensity. ${ }^{19}$ The qualitative pattern is very similar ${ }^{19}$ Although Novy (2013) estimates variable distance elasticity, his section 3.4 assumes a constant trade costs to distance parameter to focus on the equivalent of our $\varepsilon_{n i}$. 
Table 4 - Predicted bilateral trade elasticities (LN distribution)

\begin{tabular}{lccc}
\hline LHS & France & China & Average \\
\hline \multirow{3}{*}{ Total flows } & -4.513 & -4.52 & -4.517 \\
Number of exporters & $(.527)$ & $(.893)$ & $(.573)$ \\
& $(1.817$ & -2.848 & -2.832 \\
Average flows & -1.697 & $(1.502)$ & $(1.163)$ \\
& $(.777)$ & $(.713)$ & $(.666)$ \\
\hline
\end{tabular}

Notes: This table presents the predicted elasticities (mean and s.d.) on total exports, the number of exporting firms, and average export flows. Required parameters are $\sigma$, the CES, and $\nu$, the dispersion parameter of the log normal distribution.

here, with the bilateral elasticity decreasing in absolute value with the share of exports going to a destination. One can use this variance in $\varepsilon_{n i}$ to quantify the error that a practitioner would make when assuming a constant response of exports to a trade liberalization episode. Taking China as an example, decreasing trade costs by one percent would raise flows by around 6 percent for countries like Somalia, Chad or Azerbaijan (first bin of Chinese exports) and slightly more than 4 percent for the USA and Japan (top bin). Since the estimate that would be obtained when imposing a unique elasticity would be close to the average elasticity (4.52), this would entail a 25 percent underestimate of the trade growth for initially low traders (1.5/6) and an overestimate of around 12.5 percent $(.5 / 4)$ for the top trade pairs. ${ }^{20}$

\footnotetext{
${ }^{20}$ We thank Steve Redding for suggesting this quantification.
} 
Figure 9 - Variance in trade elasticities: $\varepsilon_{n \mathrm{FR}}$ and $\varepsilon_{n \mathrm{CN}}$

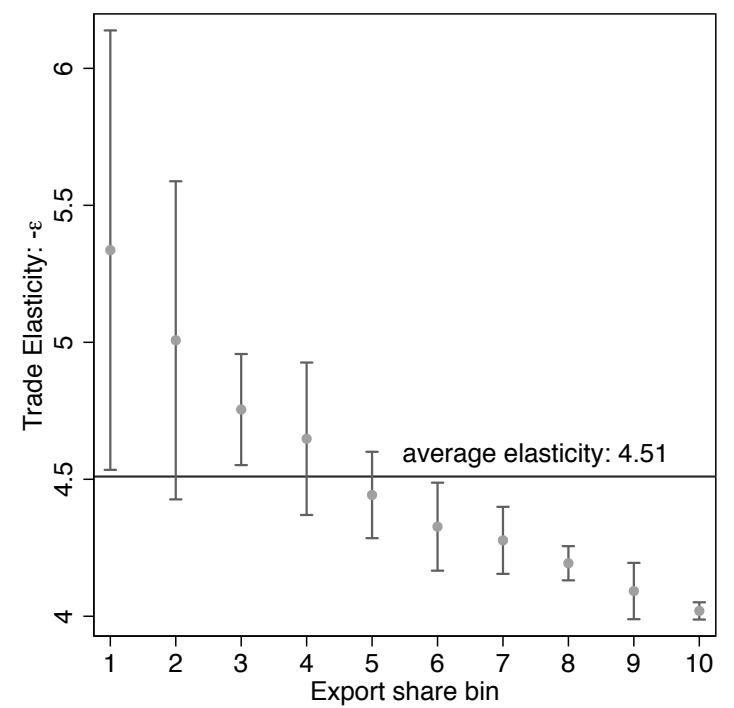

(a) French exports

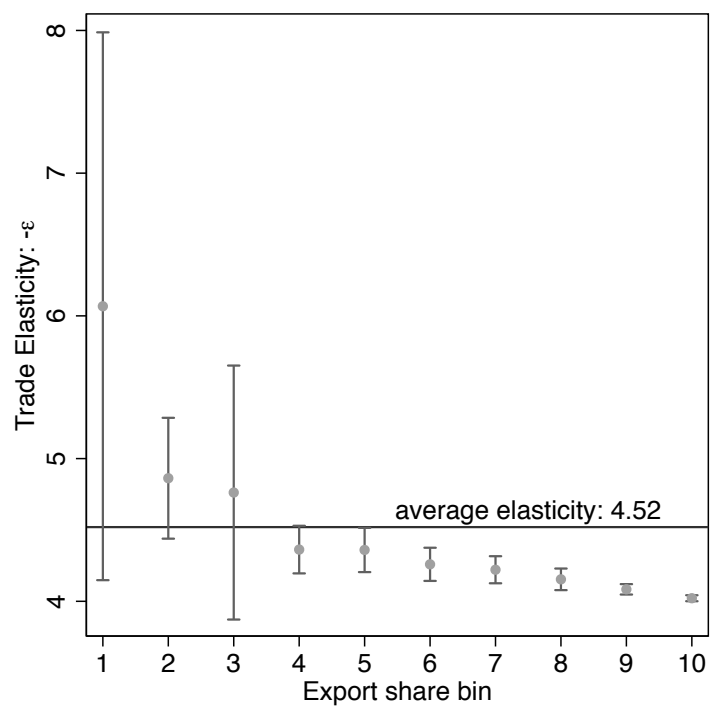

(b) Chinese exports

\subsection{Comparison with macro-based estimates of trade elasticities}

We now can turn to empirical estimates of aggregate elasticities to be compared with our predictions. Those are obtained using aggregate versions of our estimating tetrad equations presented above, which is very comparable to the method most often used in the literature: a gravity equation with country fixed effects and a set of bilateral trade costs covariates, on which a constant trade elasticity is assumed. ${ }^{21}$ Column (1) of Table 5 uses the same sample of product-markets as in our benchmark firm-level estimations and runs the regression on the tetrad of aggregate rather than individual exports. Column (2) uses the same covariates but on the count of exporters, and column (3) completes the estimation by looking at the effects on average flows. An important finding is that the effect on average trade flow is estimated at -2.55 , and is significant at the $1 \%$ level, contrary to the Pareto prediction (in which no variable trade cost should enter the equation for average flows). ${ }^{22}$ This finding is robust to controlling for RTA (column 6) or constraining the sample to positive tariffs (column 9). The estimated median trade elasticity on total flows over all

\footnotetext{
${ }^{21}$ Note that the gravity prediction on aggregate flows where origin, destination, and bilateral variables are multiplicatively separable and where there is a unique trade elasticity is only valid under Pareto. The heterogeneous elasticities generated by deviating from Pareto invalidate the usual gravity specification. Our intuition however is that the elasticity estimated using gravity/tetrads should be a reasonable approximation of the average bilateral elasticities. In order to verify this intuition, we run Monte Carlo simulations of the model with log-normal heterogeneity and find that indeed the average of micro-based heterogeneous elasticities is very close to the unique macro-based estimate in a gravity/tetrads equation on aggregate flows. Description of those simulations are in Appendix 10:

${ }^{22}$ Note that the three dependent variables are computed for each hs6 product-destination, and therefore that the average exports do not contain an extensive margin where number of products would vary across destinations.
} 
specifications at -4.79 , is very close from the -5.03 found as the median estimate in the literature by Head and Mayer (2014).

Table 5 - Elasticites of total flows, count of exporters and average trade flows.

\begin{tabular}{|c|c|c|c|c|c|c|c|c|c|}
\hline & $\begin{array}{l}\text { Tot. } \\
\text { (1) }\end{array}$ & $\begin{array}{c}\text { \# exp. } \\
(2)\end{array}$ & $\begin{array}{l}\text { Avg. } \\
\text { (3) }\end{array}$ & $\begin{array}{l}\text { Tot. } \\
\text { (4) }\end{array}$ & $\begin{array}{c}\# \text { exp. } \\
\text { (5) }\end{array}$ & $\begin{array}{c}\text { Avg. } \\
\text { (6) }\end{array}$ & $\begin{array}{l}\text { Tot. } \\
(7)\end{array}$ & $\begin{array}{c}\# \text { exp. } \\
\text { (8) }\end{array}$ & $\begin{array}{c}\text { Avg. } \\
(9)\end{array}$ \\
\hline Applied Tariff & $\begin{array}{l}-6.84^{a} \\
(0.82)\end{array}$ & $\begin{array}{l}-4.29^{a} \\
(0.66)\end{array}$ & $\begin{array}{l}-2.55^{a} \\
(0.54)\end{array}$ & $\begin{array}{l}-4.00^{a} \\
(0.73)\end{array}$ & $\begin{array}{l}-1.60^{b} \\
(0.63)\end{array}$ & $\begin{array}{l}-2.41^{a} \\
(0.50)\end{array}$ & $\begin{array}{l}-4.79^{a} \\
(0.84)\end{array}$ & $\begin{array}{l}-2.13^{a} \\
(0.50)\end{array}$ & $\begin{array}{l}-2.66^{a} \\
(0.54)\end{array}$ \\
\hline Distance & $\begin{array}{l}-0.85^{a} \\
(0.04)\end{array}$ & $\begin{array}{l}-0.61^{a} \\
(0.03)\end{array}$ & $\begin{array}{l}-0.24^{a} \\
(0.02)\end{array}$ & $\begin{array}{l}-0.51^{a} \\
(0.05)\end{array}$ & $\begin{array}{l}-0.28^{a} \\
(0.03)\end{array}$ & $\begin{array}{l}-0.23^{a} \\
(0.03)\end{array}$ & $\begin{array}{l}-0.85^{a} \\
(0.04)\end{array}$ & $\begin{array}{l}-0.60^{a} \\
(0.03)\end{array}$ & $\begin{array}{l}-0.25^{a} \\
(0.02)\end{array}$ \\
\hline Contiguity & $\begin{array}{c}0.62^{a} \\
(0.12)\end{array}$ & $\begin{array}{c}0.30^{a} \\
(0.09)\end{array}$ & $\begin{array}{c}0.32^{a} \\
(0.06)\end{array}$ & $\begin{array}{c}0.53^{a} \\
(0.11)\end{array}$ & $\begin{array}{c}0.21^{a} \\
(0.07)\end{array}$ & $\begin{array}{c}0.32^{a} \\
(0.05)\end{array}$ & $\begin{array}{c}0.64^{a} \\
(0.12)\end{array}$ & $\begin{array}{c}0.35^{a} \\
(0.09)\end{array}$ & $\begin{array}{c}0.29^{a} \\
(0.06)\end{array}$ \\
\hline Colony & $\begin{array}{c}0.93^{a} \\
(0.11)\end{array}$ & $\begin{array}{c}0.72^{a} \\
(0.10)\end{array}$ & $\begin{array}{c}0.20^{a} \\
(0.06)\end{array}$ & $\begin{array}{c}0.38^{a} \\
(0.13)\end{array}$ & $\begin{array}{c}0.20^{b} \\
(0.10)\end{array}$ & $\begin{array}{c}0.17^{b} \\
(0.08)\end{array}$ & $\begin{array}{c}1.12^{a} \\
(0.14)\end{array}$ & $\begin{array}{c}0.94^{a} \\
(0.11)\end{array}$ & $\begin{array}{c}0.17^{b} \\
(0.07)\end{array}$ \\
\hline Common language & $\begin{array}{c}0.09 \\
(0.09)\end{array}$ & $\begin{array}{c}0.16^{c} \\
(0.09)\end{array}$ & $\begin{array}{l}-0.07 \\
(0.06)\end{array}$ & $\begin{array}{c}0.39^{a} \\
(0.09)\end{array}$ & $\begin{array}{c}0.44^{a} \\
(0.08)\end{array}$ & $\begin{array}{l}-0.05 \\
(0.06)\end{array}$ & $\begin{array}{l}-0.02 \\
(0.10)\end{array}$ & $\begin{array}{c}0.05 \\
(0.08)\end{array}$ & $\begin{array}{l}-0.07 \\
(0.06)\end{array}$ \\
\hline RTA & & & & $\begin{array}{c}1.10^{a} \\
(0.11)\end{array}$ & $\begin{array}{c}1.04^{a} \\
(0.06)\end{array}$ & $\begin{array}{c}0.06 \\
(0.07)\end{array}$ & & & \\
\hline Observations & 99645 & 99645 & 99645 & 99645 & 99645 & 99645 & 41376 & 41376 & 41376 \\
\hline$R^{2}$ & 0.319 & 0.537 & 0.063 & 0.331 & 0.575 & 0.063 & 0.311 & 0.505 & 0.066 \\
\hline rmse & 1.79 & 0.79 & 1.47 & 1.77 & 0.76 & 1.47 & 1.65 & 0.75 & 1.34 \\
\hline
\end{tabular}

Notes: All estimations include fixed effects for each product-reference importer country combination. Standard errors are clustered at the destination-reference importer level. The dependent variable is the tetradic term of the logarithm of total exports at the hs6-destination-origin country level in columns (1), (4) and (7); of the number of exporting firms by hs6-destination and origin country in columns (2), (5) and (8) and of the average exports at the hs6-destination-origin country level in columns (3), (6) and (9). Applied tariff is the tetradic term of the logarithm of applied tariff plus one. Columns (7) to (9) present the estimations on the sample of positive tetraded tariffs and non-MFN tariffs. ${ }^{a},{ }^{b}$ and ${ }^{c}$ denote statistical significance levels of one, five and ten percent respectively.

Under Pareto, the aggregate elasticity should reflect fully the one on the number of exporters, and there should be no impact of tariffs on average exports. This prediction of the Pareto distribution is therefore strongly contradicted by our results. As a first pass at assessing whether, the data support the log-normal predictions, we compare the (unique) macro-based elasticity obtained in Table 5, with the corresponding average of bilateral elasticities shown in Table 4 of the preceding sub-section. The numbers obtained are quite comparable when the effects of RTAs are taken into account (columns (4) to (6)) or with positive tetrad tariffs (columns (7) to (9)). Although this is not a definitive validation of the heterogenous firms model with log-normal distribution, our results clearly favor this distributional assumption over Pareto, and provides support for the empirical relevance of non-constant trade elasticities. 


\subsection{Non-constant trade elasticity}

We can further use tetrads on aggregate trade flows in order to show direct empirical evidence of non-constant trade elasticities. Using aggregate bilateral flows from equation (10), and building tetrads with a procedure identical to the one used in Section 2.2, we obtain the (FR, CN, $n, k)$ tetrad of aggregate exports

$$
\widetilde{X}_{\{n, k\}} \equiv \frac{X_{n F R} / X_{k F R}}{X_{n C N} / X_{k C N}}=\left(\frac{\tau_{n F R} / \tau_{k F R}}{\tau_{n C N} / \tau_{k C N}}\right)^{1-\sigma} \times \frac{V_{n F R} / V_{k F R}}{V_{n C N} / V_{k C N}}
$$

Taking logs, differentiating with respect to tariffs and using the expression for the cutoff (12), we obtain

$$
\begin{array}{r}
d \ln \widetilde{X}_{\{n, k\}}=\left(1-\sigma-\gamma_{n \mathrm{FR}}\right) \times d \ln \tau_{n \mathrm{FR}}-\left(1-\sigma-\gamma_{k \mathrm{FR}}\right) \times d \ln \tau_{k \mathrm{FR}} \\
-\left(1-\sigma-\gamma_{n \mathrm{CN}}\right) \times d \ln \tau_{n \mathrm{CN}}+\left(1-\sigma-\gamma_{k \mathrm{CN}}\right) \times d \ln \tau_{k \mathrm{CN}},
\end{array}
$$

where $\gamma_{n i}$ is the elasticity of the cost performance index to a rise in the easiness of the market, defined in (14). For general distributions of heterogeneity, this elasticity is not constant across dyads as it depends on the dyad-specific cutoff $a_{n i}^{*}$. Hence, our interpretation of equation (26) is that the contribution to the (tetraded) total exports of a change in bilateral tariffs is larger for dyads that have a larger elasticity. Under Pareto, this elasticity is constant across dyads, $\gamma_{n i}^{\mathrm{P}}=1-\sigma+\theta$. Combined with equation (26) this leads to

$$
\widetilde{\varepsilon}_{\{n, k\}}^{\mathrm{P}}=\frac{d \ln \widetilde{X}_{\{n, k\}}}{d \ln \widetilde{\tau}_{\{n, k\}}}=-\theta,
$$

where $\widetilde{\tau}_{\{n, k\}}$ is the vector of tetraded trade costs. This formula states that under Pareto, the elasticity of tetrad exports to tetrad tariffs is equal to the supply-side parameter $\theta$. This transposes to the tetrad environment the well-known result of Chaney (2008) on gravity. Under non-Pareto heterogeneity, the four elasticities in (26) will remain different, a prediction we can put to a test. Results are shown in Table 6, where we pool observations for the years 2000 to 2006. Columns (1), (2) and (3) are the equivalent of the first three columns in Table 5, with the trade costs tetrads being split into its four components and the coefficients allowed to differ. The coefficients on tariffs to the destination country $n$ show that the elasticity when considering France and China as an origin country differ significantly, consistent with the non-Pareto version of heterogeneity. Coefficients related to the reference importer $k$ also differ significantly from each other, supporting further heterogeneity in the trade elasticities. A related approach is to confine identification on the destination country, neutralizing the change of reference country with a $k$ fixed effect. Those results are shown in columns (4) to (6), where again most of the tariff elasticities differ across origin countries. ${ }^{23}$

\footnotetext{
${ }^{23}$ Table A.10 shows those same estimations for the two extreme years of our sample, 2000 and 2006, with significant evidence of non-constant elasticities in most cases.
} 
Table 6 - Non-constant trade elasticity

\begin{tabular}{lccc|ccc}
\hline Dependent variable: & Tot. & \# exp. & Avg. & Tot. & \# exp. & Avg. \\
\hline & $(1)$ & $(2)$ & $(3)$ & $(4)$ & $(5)$ & $(6)$ \\
\hline & & & & & & \\
Applied Tariff & & & & & \\
& $-4.25^{a}$ & $-2.90^{a}$ & $-1.34^{a}$ & $-4.06^{a}$ & $-2.76^{a}$ & $-1.30^{a}$ \\
& $(0.27)$ & $(0.25)$ & $(0.18)$ & $(0.26)$ & $(0.23)$ & $(0.17)$ \\
Applied Tariff $_{n, \mathrm{CN}}$ & $3.43^{a}$ & $1.87^{a}$ & $1.56^{a}$ & $3.30^{a}$ & $1.76^{a}$ & $1.53^{a}$ \\
& $(0.27)$ & $(0.25)$ & $(0.17)$ & $(0.26)$ & $(0.23)$ & $(0.17)$ \\
& & & & & & \\
Applied Tariff $_{k, \mathrm{FR}}$ & $7.11^{a}$ & $6.60^{a}$ & $0.52^{b}$ & & & \\
& $(0.36)$ & $(0.20)$ & $(0.24)$ & & & \\
Applied Tariff & & & & & & \\
& $-3.79^{a}$ & $-2.14^{a}$ & $-1.66^{a}$ & & & \\
\hline Observations & $(0.40)$ & $(0.26)$ & $(0.23)$ & & & 1085643 \\
$R^{2}$ & 1077652 & 1077652 & 1077652 & 1085643 & 1085643 & 10.081 \\
rmse & 0.346 & 0.587 & 0.080 & 0.349 & 0.593 & 0.081 \\
\hline \hline
\end{tabular}

Notes: All estimations include a product and year fixed effects and the four components ( $n, \mathrm{FR}$; $n, \mathrm{CN} ; k, \mathrm{FR}$; and $k, \mathrm{CN}$ ) of each gravity control (distance, common language, contiguity and colony). In all estimations standard errors are clustered at the destination-reference country and year level.

\subsection{Micro and Aggregate elasticities at the industry level}

As a last exercise, we provide evidence that both demand and supply determinants enter the aggregate elasticity by looking at industry-level estimates. For each good, we can estimate a firm-level and an aggregate elasticity to tariffs (as in sections 4.2 and 5.3 respectively). Under the Pareto assumption, those two elasticities have no reason to be correlated, since the micro elasticity is a measure of product differentiation, while the macro one is capturing homogeneity in firms' productive efficiency. Under alternative distributions like the log-normal, the aggregate elasticity includes both determinants and therefore should be correlated with the micro one.

We run our micro and macro-level tetrad estimations for each 2-digit ISIC industry separately including destination-reference country and year fixed effects. Table 7 presents the results. Columns (1) and (2) show the coefficients for the micro-level elasticity while columns (3) and (4) report the estimates of the aggregate elasticity using the tetrad term of total exports by product-destinationreference country and year. Columns (2) and (4) restrict the sample to EU destinations. Each cell reports the coefficient on the applied tariffs tetrad by industry with associated degree of statistical significance.

Estimates at the industry level yield coefficients of the intensive margin elasticity that average to -2.67 (column 1). The coefficients of the aggregate elasticity have a mean of -3.22 (column 3 ). More important for our main investigation, the intensive and aggregate elasticities are correlated 
(pairwise correlations are .68 for the full sample, and .74 for the EU one). Figure 10 shows graphical evidence of those correlations that exhibits overwhelming evidence in favor of the aggregate elasticity including demand side determinants.

Table 7 - Micro and Aggregate elasticities by industry: 2000-2006

\begin{tabular}{lrrrr}
\hline & \multicolumn{2}{c}{ Micro } & \multicolumn{2}{c}{ Aggregate } \\
\hline Dependent variable: & firm-level & exports & \multicolumn{2}{c}{ total exports } \\
\hline & Full & EU & Full & EU \\
\hline & & & & \\
Agriculture & $-4.85^{a}$ & -3.77 & $-4.66^{a}$ & $-4.9^{c}$ \\
Food & $-2.1^{a}$ & $-3.09^{a}$ & $-3^{a}$ & $-3.57^{a}$ \\
Textile & $-1.85^{a}$ & $-5.74^{a}$ & $-1.84^{a}$ & $-2.97^{b}$ \\
Wearing & $-3.2^{a}$ & $-3.23^{a}$ & $-3.4^{a}$ & $-3.64^{a}$ \\
Leather & $-4.13^{a}$ & $-5.96^{a}$ & $-6.84^{a}$ & $-8.72^{a}$ \\
Wood & $-9.4^{a}$ & $-20.88^{a}$ & $-9.59^{a}$ & $-15.33^{a}$ \\
Paper & $8.39^{a}$ & 6.35 & $6.64^{b}$ & 8.34 \\
Edition & 1.68 & 2.2 & $5.02^{b}$ & 3.86 \\
Coke prod & .02 & 1.39 & .93 & 1.21 \\
Chemical & $-4.99^{a}$ & $-7.29^{a}$ & $-5.64^{a}$ & $-7.66^{a}$ \\
Rubber & $5.12^{a}$ & $4.8^{a}$ & $12.18^{a}$ & $16.25^{a}$ \\
Basic metal & $-4.55^{a}$ & $-7.35^{a}$ & $-3.17^{c}$ & $-6.27^{c}$ \\
Metal products & $-2.9^{a}$ & $-6.33^{a}$ & $-1.11^{c}$ & $-3.32^{a}$ \\
Machinery & $-3.18^{a}$ & $-6.92^{a}$ & $-2.89^{a}$ & $-5.06^{a}$ \\
Office & -.06 & -4.88 & $-21.14^{a}$ & $-31.42^{b}$ \\
Electrical Prod & $-2.49^{b}$ & $-8.44^{a}$ & -.59 & -1.34 \\
Equip. Radio, TV & $-8.38^{a}$ & $-10.66^{a}$ & $-7.08^{a}$ & $-8.1^{a}$ \\
Medical instruments & $-2.36^{a}$ & $-3.9^{b}$ & -.38 & -.29 \\
Vehicles & $-4.14^{c}$ & $12.69^{c}$ & $-5.38^{a}$ & $15.52^{a}$ \\
Transport & $-11.34^{a}$ & $-18.28^{a}$ & $-16.15^{a}$ & $-17.37^{a}$ \\
Furniture & $-1.35^{b}$ & $-3.75^{a}$ & .26 & 0 \\
\hline \hline
\end{tabular}

Notes: All estimations are run by industry 2 digit. The cells report the coefficient on the applied tariffs tetrad by industry. All estimations include destination-reference country and year fixed effects. Standard errors are clustered by product-reference country and year. All estimations include a constant that is not reported. Applied tariff is the tetradic term of the logarithm of applied tariff plus one. ${ }^{a},{ }^{b}$ and ${ }^{c}$ denote statistical significance levels of one, five and ten percent respectively. 
Figure 10 - Aggregate and intensive margin elasticities by industry 2 digit

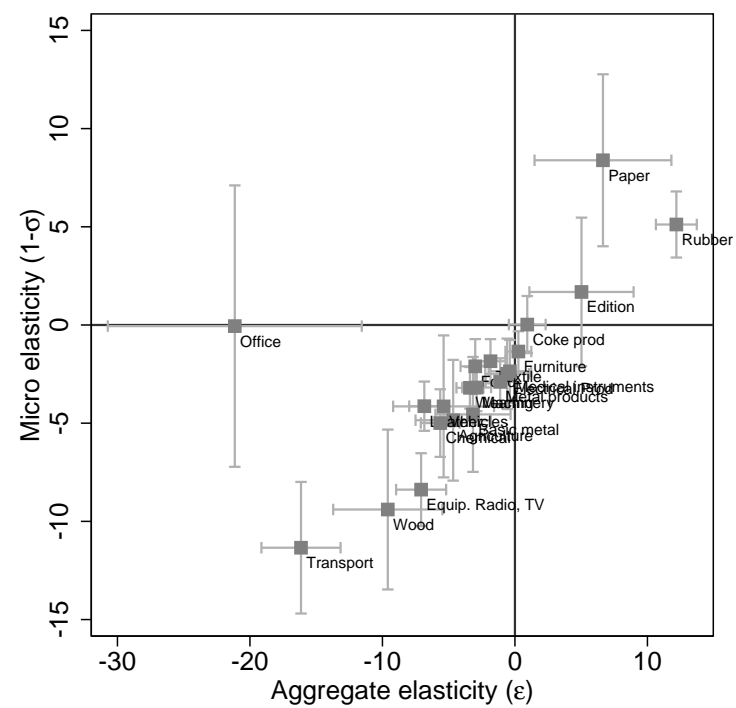

(a) Full set

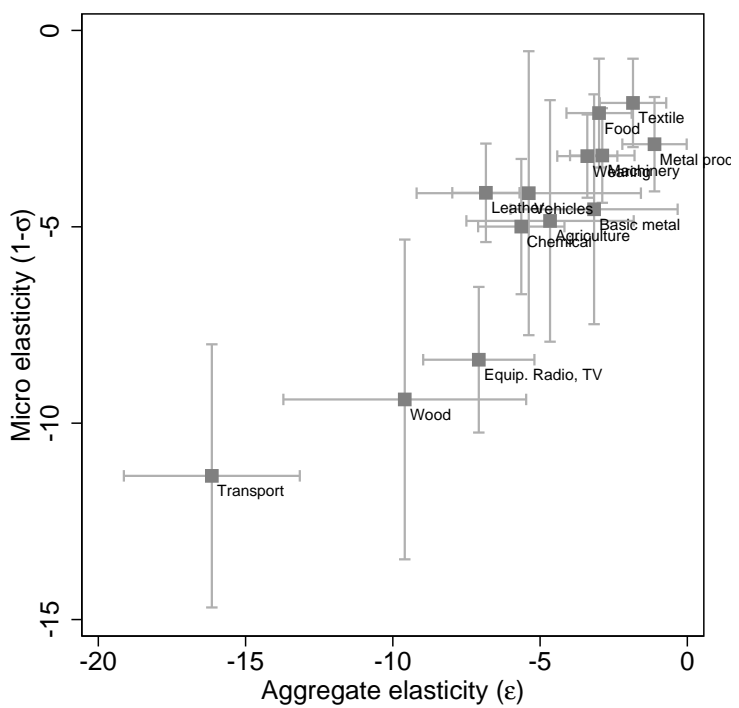

(b) Coeff sig. $<0$

\section{Conclusion}

We have argued in this paper that knowledge of the firm-level response to trade costs is a central element to our understanding of aggregate export reaction. In other words, we need micro-level data to understand the macro-level impacts of trade costs, a central element in any trade policy evaluation. This need for micro data is presumably true with the vast majority of possible heterogeneity distribution assumptions. There is one exception however where micro data is not needed to estimate the aggregate elasticity: the (untruncated) Pareto distribution. It is an exception the literature has been concentrating on for reasons of tractability that are perfectly legitimate, but the evidence presented in our paper points to systematic variation in bilateral aggregate trade elasticities that is both substantial and compatible with log-normal heterogeneity (in addition to be strongly preferred when looking at the micro-level distribution of export sales). We therefore call for a "micro approach" to estimating those elasticities as opposed to the "macro approach" using gravity specified so as to estimate a constant elasticity.

The micro- and macro- approaches differ substantially in several respects. On the one hand, gravity is a more direct and parsimonious route for estimating aggregate elasticities: (i) parametric assumptions are reduced to a minimum while our micro-based procedure depends on the calibration of the productivity distribution; (ii) gravity is less demanding in terms of data and makes possible the use of easily accessible dataset of bilateral aggregate trade flows. On the other hand, gravity provides, for each origin country, only a cross-destination average of elasticities while the microbased approach provides the full cross-dyadic distribution of elasticities. Given this last limitation, we use our gravity estimates of averaged elasticities as a benchmark for discriminating between the 
two distributional assumptions made in our micro-based quantifications. We find that average value of bilateral trade elasticities obtained under a log-normal calibration is very close to the empirical gravity estimate which constrains the elasticity to be constant across country pairs. By contrast, the Pareto-based calibration leads to predictions that seem invalidated by the data. Namely, the invariance of average shipments to ad-valorem tariff variations, the lack of correlation between firmlevel and aggregate level of elasticities estimated industry by industry, and the constant aggregate trade elasticities.

\section{References}

Anderson, J. E. and van Wincoop, E. (2003). Gravity with gravitas: A solution to the border puzzle. American Economic Review, 93 (1):170-192.

Arkolakis, C. (2010). Market penetration costs and the new consumers margin in international trade. Journal of Political Economy, 118(6):1151 - 1199.

Arkolakis, C., Costinot, A., and Rodríguez-Clare, A. (2010). Gains from trade under monopolistic competition: A simple example with translog expenditure functions and pareto distributions of firm-level productivity. manuscript.

Arkolakis, C., Costinot, A., and Rodriguez-Clare, A. (2012). New trade models, same old gains? American Economic Review, 102(1):94-130.

Atkeson, A. and Burstein, A. (2008). Pricing-to-market, trade costs, and international relative prices. The American Economic Review, 98(5):1998-2031.

Baier, S. and Bergstrand, J. H. (2001). The growth of world trade: tariffs, transport costs, and income similarity. Journal of International Economics, 53 (1):1-27.

Barba Navaretti, G., Bugamellli, M., Forlani, E., and Ottaviano, G. (2015). It takes (more than) a moment: Revisiting the link between firm productivity and aggregate exports. University of Milan Mimeo.

Berman, N., Martin, P., and Mayer, T. (2012). How do different exporters react to exchange rate changes? The Quarterly Journal of Economics, 127 (1):437-492.

Berthou, A. and Fontagné, L. (2015). Variable trade costs, composition effects, and the intensive margin of trade. Technical Report 543, Banque de France.

Broda, C. and Weinstein, D. (2006). Globalization and the gains from variety. Quarterly Journal of Economics, 121 (2):541-585.

Caliendo, L. and Parro, F. (2015). Estimates of the trade and welfare effects of nafta. Review of Economic Studies, 82(1):1-44.

Chaney, T. (2008). Distorted gravity: The intensive and extensive margins of international trade. American Economic Review, 98 (4):1707-1721.

Costinot, A., Donaldson, D., and Komunjer, I. (2012). What goods do countries trade? a quantitative exploration of ricardo's ideas. Review of Economic Studies, 79(2):581-608. 
Crozet, M., Head, K., and Mayer, T. (2012). Quality sorting and trade: Firm-level evidence for french wine. Review of Economic Studies, 79(2):609 - 644.

Eaton, J. and Kortum, S. (2001). Trade in capital goods. European Economic Review, 45(7):11951235.

Eaton, J. and Kortum, S. (2002). Technology, geography, and trade. Econometrica, 70 (5):17411779.

Eaton, J., Kortum, S., and Kramarz, F. (2011). An anatomy of international trade: Evidence from French firms. Econometrica, 79(5):1453-1498.

Feenstra, R. C. (1994). New product varieties and the measurement of international prices. American Economic Review, 84:157-177.

Feenstra, R. C. (2003). A homothetic utility function for monopolistic competition models. Economics Letters, 78(2):79-86.

Feenstra, R. C. (2013). Restoring the product variety and pro-competitive gains from trade with heterogeneous firms and bounded productivity. UC Davis Mimeo.

Fitzgerald, D. and Haller, S. (2014). Exporters and shocks: Dissecting the international elasticity puzzle. manuscript.

Freund, C. and Pierola, M. D. (2015). Export superstars. Review of Economics and Statistics.

Hallak, J. C. (2006). Product quality and the direction of trade. Journal of International Economics, 68 (1):238-265.

Harrigan, J. and Deng, H. (2010). ChinaâĂŹs local comparative advantage. In Feenstra, R. C. and Wei, S.-J., editors, ChinaâĂŹs Growing Role in World Trade, NBER Conference volume, volume 3. Chicago University.

Head, K. and Mayer, T. (2014). Gravity equations: Workhorse, toolkit, and cookbook. In Helpman, E., Gopinath, G., and Rogoff, K., editors, Handbook of International Economics, volume 4. Elsevier.

Head, K., Mayer, T., and Ries, J. (2010). The erosion of colonial trade linkages after independence. Journal of International Economics, 81 (1):1-14.

Head, K., Mayer, T., and Thoenig, M. (2014). Welfare and trade without pareto. American Economic Review, 104(5):310-16.

Head, K. and Ries, J. (2001). Increasing returns versus national product differentiation as an explanation for the pattern of us-canada trade. American Economic Review, 91(4):858-876.

Helpman, E., Melitz, M., and Rubinstein, Y. (2008). Estimating trade flows: Trading partners and trading volumes. Quarterly Journal of Economics, 123(2):441-487.

Hummels, D. (1999). Towards a geography of trade costs. Technical Report 17, GTAP Working Paper.

Imbs, J. and Méjean, I. (2014). Elasticity optimism. American Economic Journal: Macroeconomics. Krugman, P. (1980). Scale economies, product differentiation, and the pattern of trade. American Economic Review, 70:950-959. 
Melitz, M. (2003). The impact of trade on intra-industry reallocations and agregate industry productivity. Econometrica, 71:1695-1725.

Melitz, M. and Ottaviano, G. (2008). Market size, trade, and productivity. Review of Economic Studies, 75(1):295-316.

Melitz, M. J. and Redding, S. J. (2015). New trade models, new welfare implications. American Economic Review.

Novy, D. (2013). International trade without CES: Estimating translog gravity. Journal of International Economics, 89(2):271-282.

Ossa, R. (2012). Why trade matters after all. Working Paper 18113, NBER.

Romalis, J. (2007). Nafta's and cusfta's impact on international trade. Review of Economics and Statistics, 89(3):416 - 435.

Simonovska, I. and Waugh, M. (2012). Different trade models, different trade elasticities? UC Davis and NYU Stern School of Business. Available at: http://www. econ. ucdavis. edu/faculty/sina/sw2.pdf.

Simonovska, I. and Waugh, M. E. (2011). The elasticity of trade: Estimates and evidence. Working Paper 16796, NBER.

Wooldridge, J. W. (2006). Cluster sample methods in applied econometrics: An extended analysis. Working paper, Michigan State University.

Yang, M.-J. (2014). Firm heterogeneity and trade in a distorted gravity world. University of Washington Mimeo. 


\section{Appendix}

\section{Appendix 8:. Empirical Appendix}

\section{A.8.1.. Descriptive statistics}

Table A.1 - Average percentage point difference between the applied tariff to France and China across industries by Germany and Japan (2000)

\begin{tabular}{lrr|rr}
\hline Reference importer: & \multicolumn{2}{c|}{ Germany } & \multicolumn{2}{c}{ Japan } \\
\hline & $\begin{array}{c}\text { Full } \\
\text { sample }\end{array}$ & $\begin{array}{r}\text { Tetrad } \\
\text { regression sample }\end{array}$ & $\begin{array}{c}\text { Full } \\
\text { sample }\end{array}$ & $\begin{array}{r}\text { Tetrad } \\
\text { regression sample }\end{array}$ \\
\hline & & & & \\
Agriculture & -3.27 & -2.98 & .01 & .02 \\
Food & -7.83 & -9.63 & 1.24 & 1.45 \\
Textile & -7.14 & -6.95 & 5.31 & 4.58 \\
Wearing apparel & -9.34 & -8.11 & 6.2 & 6.79 \\
Leather & -1.5 & -1.15 & 8.4 & 4.68 \\
Wood & -1.36 & -1.47 & 2.66 & 3.69 \\
Paper & 0 & 0 & 1.39 & 1.3 \\
Edition & -.79 & -.65 & .26 & .64 \\
Coke prod & 0 & 0 & .97 & 1.73 \\
Chemical & -1.01 & -.74 & 2.51 & 2.4 \\
Rubber \& Plastic & -1.37 & -1.25 & 2.5 & 2.37 \\
Non Metallic & -1.43 & -2.18 & 1.16 & .8 \\
Basic metal products & -1.84 & -3.56 & 1.89 & 2.75 \\
Metal products & -.67 & -.99 & 1.38 & 1.32 \\
Machinery & -.25 & -.3 & .19 & 0 \\
Office & -.16 & -.38 & 0 & 0 \\
Electrical Prod & -.38 & -.47 & .37 & .62 \\
Equip. Radio, TV & -1.72 & -1.79 & 0 & 0 \\
Medical instruments & -.58 & -.41 & .14 & .34 \\
Vehicles & -2.22 & -1.63 & 0 & 0 \\
Transport & -1.27 & -1.37 & 0 & 1.95 \\
Furniture & -.51 & -.63 & 1.93 & \\
\hline & & & & 0 \\
\end{tabular}


Table A.2 - Destination countries characteristics in 2000

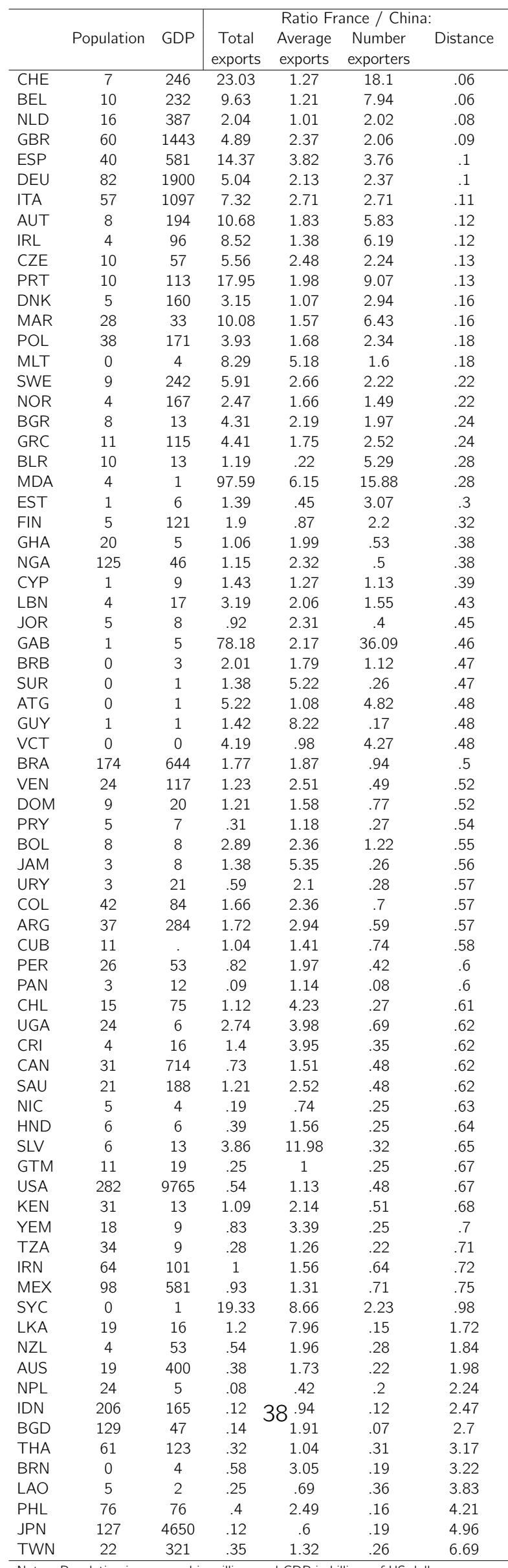


Table A.3 - Avg. difference between tariffs applied to France and China. Full sample

\begin{tabular}{|c|c|c|c|c|c|c|}
\hline & $\begin{array}{c}\text { France }< \\
\text { Tariff }\end{array}$ & $\begin{array}{c}\text { China } \\
\text { \# HS6 }\end{array}$ & $\begin{array}{r}\text { France } \\
\text { Tariff }\end{array}$ & $\begin{array}{c}\text { China } \\
\text { \# HS6 }\end{array}$ & $\begin{array}{c}\text { France }> \\
\text { Tariff }\end{array}$ & $\begin{array}{c}\text { China } \\
\text { \# HS6 }\end{array}$ \\
\hline ARG & . & 0 & 0 & 5113 & . & 0 \\
\hline ATG & . & 0 & 0 & 5097 & & 0 \\
\hline AUS & . & 0 & 0 & 4188 & 1.91 & 905 \\
\hline AUT & -5.7 & 2137 & 0 & 2825 & . & 0 \\
\hline BEL & -5.7 & 2137 & 0 & 2825 & . & 0 \\
\hline BGD & . & 0 & 0 & 5106 & . & 0 \\
\hline BGR & . & 0 & 0 & 5059 & . & 0 \\
\hline BLR & . & 0 & 0 & 4559 & . & 0 \\
\hline $\mathrm{BOL}$ & . & 0 & 0 & 5113 & . & 0 \\
\hline BRA & . & 0 & 0 & 5113 & . & 0 \\
\hline BRB & . & 0 & 0 & 2020 & . & 0 \\
\hline BRN & . & 0 & 0 & 5079 & . & 0 \\
\hline CAN & -3.87 & 15 & 0 & 2877 & 3.07 & 2178 \\
\hline $\mathrm{CHE}$ & -10 & 1 & 0 & 4120 & . & 0 \\
\hline $\mathrm{CHL}$ & . & 0 & 0 & 5113 & . & 0 \\
\hline $\mathrm{COL}$ & . & 0 & 0 & 5113 & . & 0 \\
\hline CRI & . & 0 & 0 & 5113 & . & 0 \\
\hline CUB & . & 0 & 0 & 5112 & . & 0 \\
\hline CYP & . & 0 & 0 & 4929 & . & 0 \\
\hline CZE & . & 0 & 0 & 5113 & . & 0 \\
\hline DEU & -5.7 & 2137 & 0 & 2825 & . & 0 \\
\hline DNK & -5.7 & 2137 & 0 & 2825 & . & 0 \\
\hline DOM & . & 0 & 0 & 5008 & . & 0 \\
\hline ESP & -5.7 & 2137 & 0 & 2825 & . & 0 \\
\hline EST & & 0 & 0 & 5113 & . & 0 \\
\hline FIN & -5.7 & 2137 & 0 & 2825 & . & 0 \\
\hline GAB & . & 0 & 0 & 5108 & . & 0 \\
\hline GBR & -5.7 & 2137 & 0 & 2825 & . & 0 \\
\hline GHA & . & 0 & 0 & 5019 & . & 0 \\
\hline GRC & -5.7 & 2137 & 0 & 2825 & . & 0 \\
\hline GTM & . & 0 & 0 & 5113 & . & 0 \\
\hline GUY & . & 0 & 0 & 2043 & . & 0 \\
\hline HND & . & 0 & 0 & 5113 & . & 0 \\
\hline IDN & . & 0 & 0 & 5110 & . & 0 \\
\hline IRL & -5.7 & 2137 & 0 & 2825 & . & 0 \\
\hline IRN & . & 0 & 0 & 5113 & . & 0 \\
\hline ITA & -5.7 & 2137 & 0 & 2825 & . & 0 \\
\hline JAM & . & 0 & 0 & 5113 & . & 0 \\
\hline JOR & . & 0 & 0 & 5085 & . & 0 \\
\hline JPN & -.18 & 3 & 0 & 2771 & 4.06 & 2256 \\
\hline KEN & . & 0 & 0 & 4554 & . & 0 \\
\hline LAO & . & 0 & 0 & 4977 & . & 0 \\
\hline LBN & . & 0 & 0 & 5067 & . & 0 \\
\hline LKA & . & 0 & 0 & 5090 & . & 0 \\
\hline MAR & . & 0 & 0 & 5113 & . & 0 \\
\hline MDA & . & 0 & 0 & 5068 & . & 0 \\
\hline MEX & . & 0 & 0 & 5084 & . & 0 \\
\hline MLT & . & 0 & 0 & 5109 & . & 0 \\
\hline NGA & . & 0 & 0 & 5113 & . & 0 \\
\hline $\mathrm{NIC}$ & . & 0 & 0 & 5113 & . & 0 \\
\hline NLD & -5.7 & 2137 & 0 & 2825 & . & 0 \\
\hline NOR & -10.74 & 1210 & 0 & 3560 & . & 0 \\
\hline NPL & . & 0 & 0 & 5096 & . & 0 \\
\hline NZL & . & 0 & 0 & 3220 & 1.15 & 1876 \\
\hline PAN & . & 0 & 0 & 5110 & . & 0 \\
\hline PER & . & 0 & 0 & 5113 & . & 0 \\
\hline PHL & . & 0 & 0 & 5112 & . & 0 \\
\hline POL & -9.51 & 4234 & 0 & 485 & 7.14 & 388 \\
\hline PRT & -5.7 & 2137 & 0 & 2825 & . & 0 \\
\hline PRY & . & 0 & 0 & 5113 & . & 0 \\
\hline SAU & . & 0 & 0 & 4799 & . & 0 \\
\hline SLV & . & 0 & 0 & 5113 & . & 0 \\
\hline SUR & . & 0 & 0 & 1170 & . & 0 \\
\hline SWE & -5.7 & 2137 & 0 & 2825 & . & 0 \\
\hline SYC & . & 0 & 0 & 4849 & . & 0 \\
\hline THA & . & 0 & 0 & 5056 & . & 0 \\
\hline TWN & . & 0 & 0 & 5113 & . & 0 \\
\hline TZA & . & 0 & 39 & 5113 & . & 0 \\
\hline UGA & . & 0 & 0 & 5110 & . & 0 \\
\hline URY & . & 0 & 0 & 4829 & . & 0 \\
\hline USA & . & 0 & 0 & 4768 & & 0 \\
\hline VCT & . & 0 & 0 & 2040 & . & 0 \\
\hline VEN & . & 0 & 0 & 5109 & . & 0 \\
\hline YEM & . & 0 & 0 & 5111 & . & 0 \\
\hline
\end{tabular}


Table A.4 - Avg. difference between tariffs applied to France and China. Tetrad sample.

\begin{tabular}{|c|c|c|c|c|c|c|}
\hline & $\begin{array}{c}\text { France }< \\
\text { Tariff }\end{array}$ & $\begin{array}{l}\text { China } \\
\text { \# HS6 }\end{array}$ & $\begin{array}{c}\text { France }= \\
\text { Tariff }\end{array}$ & $\begin{array}{l}\text { China } \\
\text { \# HS6 }\end{array}$ & $\begin{array}{c}\text { France }> \\
\text { Tariff }\end{array}$ & $\begin{array}{l}\text { China } \\
\text { \# HS6 } \\
\end{array}$ \\
\hline ARG & . & 0 & 0 & 567 & 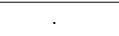 & 0 \\
\hline ATG & & 0 & 0 & 1 & & 0 \\
\hline AUS & & 0 & 0 & 816 & 1.87 & 249 \\
\hline AUT & -6.06 & 357 & 0 & 377 & & 0 \\
\hline BEL & -5.43 & 651 & 0 & 772 & . & 0 \\
\hline BGD & & 0 & 0 & 73 & & 0 \\
\hline BGR & & 0 & 0 & 121 & . & 0 \\
\hline BLR & . & 0 & 0 & 9 & . & 0 \\
\hline $\mathrm{BOL}$ & & 0 & 0 & 11 & . & 0 \\
\hline BRA & . & 0 & 0 & 636 & . & 0 \\
\hline BRB & . & 0 & 0 & 5 & . & 0 \\
\hline BRN & . & 0 & 0 & 6 & & 0 \\
\hline CAN & - & 0 & 0 & 424 & 2.78 & 571 \\
\hline CHE & -10 & 1 & 0 & 658 & . & 0 \\
\hline $\mathrm{CHL}$ & & 0 & 0 & 419 & & 0 \\
\hline $\mathrm{COL}$ & . & 0 & 0 & 183 & . & 0 \\
\hline CRI & & 0 & 0 & 37 & & 0 \\
\hline CUB & . & 0 & 0 & 25 & . & 0 \\
\hline CYP & & 0 & 0 & 255 & & 0 \\
\hline CZE & & 0 & 0 & 434 & . & 0 \\
\hline DEU & -5.58 & 831 & 0 & 982 & & 0 \\
\hline DNK & -5.74 & 465 & 0 & 500 & & 0 \\
\hline DOM & & 0 & 0 & 56 & . & 0 \\
\hline ESP & -5.41 & 720 & 0 & 859 & & 0 \\
\hline EST & & 0 & 0 & 52 & . & 0 \\
\hline FIN & -5.47 & 367 & 0 & 412 & . & 0 \\
\hline GAB & & 0 & 0 & 24 & . & 0 \\
\hline GBR & -5.55 & 802 & 0 & 964 & . & 0 \\
\hline GHA & & 0 & 0 & 37 & . & 0 \\
\hline GRC & -5.37 & 446 & 0 & 556 & & 0 \\
\hline GTM & . & 0 & 0 & 51 & . & 0 \\
\hline GUY & & 0 & 0 & 2 & & 0 \\
\hline HND & . & 0 & 0 & 19 & . & 0 \\
\hline IDN & & 0 & 0 & 457 & & 0 \\
\hline IRL & -5.32 & 257 & 0 & 291 & . & 0 \\
\hline IRN & & 0 & 0 & 162 & & 0 \\
\hline ITA & -5.43 & 760 & 0 & 895 & & 0 \\
\hline JAM & . & 0 & 0 & 17 & . & 0 \\
\hline JOR & & 0 & 0 & 206 & & 0 \\
\hline JPN & -.01 & 1 & 0 & 631 & 4.09 & 535 \\
\hline KEN & & 0 & 0 & 74 & & 0 \\
\hline LAO & . & 0 & 0 & 1 & . & 0 \\
\hline LBN & & 0 & 0 & 401 & & 0 \\
\hline LKA & . & 0 & 0 & 128 & . & 0 \\
\hline MAR & & 0 & 0 & 407 & & 0 \\
\hline MDA & . & 0 & 0 & 3 & . & 0 \\
\hline MEX & & 0 & 0 & 533 & & 0 \\
\hline MLT & . & 0 & 0 & 130 & . & 0 \\
\hline NGA & & 0 & 0 & 116 & & 0 \\
\hline $\mathrm{NIC}$ & & 0 & 0 & 5 & . & 0 \\
\hline NLD & -5.64 & 748 & 0 & 920 & & 0 \\
\hline NOR & -8.03 & 267 & 0 & 248 & & 0 \\
\hline NPL & . & 0 & 0 & 15 & & 0 \\
\hline NZL & & 0 & 0 & 189 & 1.09 & 308 \\
\hline PAN & . & 0 & 0 & 125 & . & 0 \\
\hline PER & & 0 & 0 & 119 & & 0 \\
\hline PHL & & 0 & 0 & 420 & & 0 \\
\hline POL & -9.6 & 564 & 0 & 41 & 8.1 & 9 \\
\hline PRT & -4.78 & 396 & 0 & 426 & . & 0 \\
\hline PRY & & 0 & 0 & 45 & . & 0 \\
\hline SAU & . & 0 & 0 & 512 & . & 0 \\
\hline SLV & & 0 & 0 & 27 & . & 0 \\
\hline SUR & & 0 & 0 & 1 & . & 0 \\
\hline SWE & -5.94 & 489 & 0 & 511 & . & 0 \\
\hline SYC & . & 0 & 0 & 1 & . & 0 \\
\hline THA & & 0 & 0 & 662 & & 0 \\
\hline TWN & & 0 & 0 & 864 & & 0 \\
\hline TZA & . & 0 & $\begin{array}{ll}0 & 40\end{array}$ & 13 & . & 0 \\
\hline UGA & & 0 & 0 & 6 & & 0 \\
\hline URY & . & 0 & 0 & 180 & . & 0 \\
\hline USA & & 0 & 0 & 1809 & & 0 \\
\hline VCT & . & 0 & 0 & 1 & . & 0 \\
\hline VEN & & 0 & 0 & 258 & & 0 \\
\hline YEM & & 0 & 0 & 59 & & 0 \\
\hline
\end{tabular}




\section{A.8.2.. Alternative specifications of the intensive margin estimates}

\section{A.8.2.1.. Identification across products}

Estimations on the intensive margin trade elasticity in the main text exploit variation of applied tariffs within hs 6 products across destination countries and exporters (firms located in France and China). This section presents a set of estimations on alternative specifications that exploits the variation of applied tariffs within destination countries across hs6-products.

Table A.5 reports the results from estimations including a destination-reference importer country fixed effect. In this case, standard errors are clustered by hs6-reference importer country. Including these fixed effects implies that the source of identification comes from variations within destination countries across hs6-products in applied tariffs to both origin countries, France and China, by the reference importer countries. Columns (1) and (3) present estimations on the full sample, while columns (2) and (4) report estimations on the sample of positive tetraded tariffs. The trade elasticity ranges from -3.57 to -5.07 . Estimations in columns (5) and (6) restrict the destination countries to be the ones applying non-MFN duties and in column (7) to EU destination countries including countries with EU-trade agreements as Norway and Switzerland. The sample size drops radically, with the trade elasticities remaining of the expected sign and order of magnitude, but losing in statistical significance.

Table A.5 - Intensive margin elasticities. Within-country estimations.

\begin{tabular}{|c|c|c|c|c|c|c|c|}
\hline \multirow{3}{*}{$\begin{array}{l}\text { Dependent variable: } \\
\text { Sample: }\end{array}$} & \multirow{2}{*}{\multicolumn{2}{|c|}{$\begin{array}{c}\text { Top } 1 \\
\text { firm-level exports } \\
\text { Full }\end{array}$}} & \multicolumn{5}{|c|}{$\begin{array}{c}\text { Top } 1 \text { to } 10 \\
\text { firm-level exports }\end{array}$} \\
\hline & & & & & non- & AFN & EU \\
\hline & $(1)$ & (2) & (3) & (4) & (5) & (6) & $(7)$ \\
\hline Applied Tariff & $\begin{array}{l}-3.53^{a} \\
(1.07)\end{array}$ & $\begin{array}{l}-3.59^{a} \\
(1.26)\end{array}$ & $\begin{array}{l}-3.10^{a} \\
(0.70)\end{array}$ & $\begin{array}{l}-5.07^{a} \\
(0.83)\end{array}$ & $\begin{array}{l}-2.93^{a} \\
(0.83)\end{array}$ & $\begin{array}{l}-5.28^{a} \\
(0.94)\end{array}$ & $\begin{array}{l}-2.48^{a} \\
(0.61)\end{array}$ \\
\hline Observations & 37396 & 15477 & 99645 & 41376 & 12992 & 9421 & 54198 \\
\hline$R^{2}$ & 0.001 & 0.002 & 0.001 & 0.003 & 0.001 & 0.004 & 0.000 \\
\hline rmse & 2.92 & 2.93 & 3.02 & 3.05 & 3.09 & 3.06 & 2.95 \\
\hline
\end{tabular}

Notes: All estimations include destination-reference importing country fixed effects Standard errors are clustered by hs6-reference importing country. Applied tariff is the tetradic term of the logarithm of applied tariff plus one. Columns (5) and (6) present the estimations for the non-MFN sample. Columns (2), (4) and (6) present estimations on the sample of positive tetraded tariffs. ${ }^{a},{ }^{b}$ and ${ }^{c}$ denote statistical significance levels of one, five and ten percent respectively.

\section{A.8.2.2.. Cross-section estimations in 2001 and 2006}

Results in the main text focus on cross-sectional analysis of the year 2000 (before entry of China into WTO). We now turn to additional cross-section evidence after China entry into WTO (2001) 
and for the final year of our sample (2006), in Table A.6. Estimations in columns (1) and (3) include a fixed effect identifying the product-reference country combination while columns (2) and (4) include a fixed effect identifying the destination-reference importing country. As expected the coefficients on tariffs are lower since the difference of tariffs applied to France and China by destination countries is reduced after 2001. The implied values of $\sigma$ range from -3.6 to almost -2 .

Table A.6 - Intensive margin: cross-section 2001 and 2006

\begin{tabular}{lcccc}
\hline Dependent variable: & \multicolumn{2}{c}{ Top 1 to 10 firm-level exports } \\
& $(1)$ & $(2)$ & $(3)$ & $(4)$ \\
\hline \multirow{3}{*}{ Applied Tariff } & $-1.83^{a}$ & $-2.59^{a}$ & $-0.95^{b}$ & $-1.42^{b}$ \\
& $(0.64)$ & $(0.68)$ & $(0.42)$ & $(0.61)$ \\
& & & & \\
Distance & $-0.62^{a}$ & & $-0.54^{a}$ & \\
& $(0.02)$ & & $(0.02)$ & \\
Contiguity & $0.75^{a}$ & & $0.98^{a}$ & \\
& $(0.08)$ & & $(0.06)$ & \\
Colony & & & & \\
& -0.02 & & $0.49^{a}$ & \\
Common language & $-0.13^{b}$ & & $0.07)$ & \\
& $(0.06)$ & & $(0.05)$ & \\
\hline Observations & 111039 & 111039 & 217732 & 217732 \\
$R^{2}$ & 0.129 & 0.000 & 0.107 & 0.000 \\
rmse & 2.46 & 3.04 & 2.45 & 2.96 \\
\hline \hline
\end{tabular}

Notes: Estimations in columns (1) and (3) include a fixed effect identifying the hs6 product-reference importing country and standard errors are clustered by destination-reference importer country. Estimations in columns (2) and (4) include a fixed effect identifying the destination-reference importing country and standard errors are clustered by hs6 product-reference importer country. Applied tariff is the tetradic term of the logarithm of applied tariff plus one. ${ }^{a}{ }^{b}$ and ${ }^{c}$ denote statistical significance levels of one, five and ten percent respectively.

\section{A.8.2.3.. Panel estimations 2000-2006}

Our dataset spans over the 2000-2006 period. This dimension allows to identify the variation of tariffs within product-destination over time and across reference countries. Table A.7 reports 
results. Columns (1) and (3) present the baseline estimation for the 2000-2006 period, columns (2) and (5) present estimations on the sample of non-MFN destinations and columns (3) and (6) on the sample of EU destination countries. All estimations include product-destination, year and importing reference country fixed effects. The coefficients of the intensive margin elasticity are close to the findings from the cross-section estimations of 2000, and they range from -5.26 to -1.80 .

Table A.7 - Intensive margin elasticities. Within-product-destination country estimations 20002006

\begin{tabular}{lccc|ccc}
\hline \multirow{2}{*}{ Dependent variable: } & \multicolumn{3}{c|}{ Top 1 } & \multicolumn{3}{c}{ Top 1 to 10 } \\
& $(1)$ & $(2)$ & $(3)$ & $(4)$ & $(5)$ & $(6)$ \\
\hline \multirow{3}{*}{ Applied Tariff } & & & & & & \\
& $-3.20^{a}$ & $-2.47^{a}$ & $-5.26^{a}$ & $-1.99^{a}$ & $-1.80^{a}$ & $-3.66^{a}$ \\
& $(0.40)$ & $(0.62)$ & $(0.57)$ & $(0.25)$ & $(0.39)$ & $(0.36)$ \\
Distance & & & & & & \\
& $-0.38^{a}$ & $-0.44^{a}$ & $-0.28^{a}$ & $-0.45^{a}$ & $-0.51^{a}$ & $-0.35^{a}$ \\
& $(0.01)$ & $(0.02)$ & $(0.01)$ & $(0.01)$ & $(0.01)$ & $(0.01)$ \\
Contiguity & & & & & & \\
& $0.28^{a}$ & $0.23^{a}$ & $0.31^{a}$ & $0.53^{a}$ & $0.52^{a}$ & $0.31^{a}$ \\
Common language & $(0.03)$ & $(0.04)$ & $(0.03)$ & $(0.02)$ & $(0.03)$ & $(0.02)$ \\
& $-0.31^{a}$ & $-0.44^{a}$ & $-0.24^{a}$ & $-0.24^{a}$ & $-0.35^{a}$ & $-0.11^{a}$ \\
& $(0.04)$ & $(0.05)$ & $(0.05)$ & $(0.03)$ & $(0.03)$ & $(0.03)$ \\
\hline Observations & 379644 & 61882 & 198629 & 1077652 & 167758 & 558424 \\
$R^{2}$ & 0.081 & 0.099 & 0.060 & 0.085 & 0.109 & 0.060 \\
rmse & 2.23 & 2.11 & 2.27 & 2.48 & 2.37 & 2.50 \\
\hline \hline
\end{tabular}

Notes: All estimations include hs6-destination country, reference importing country and year fixed effects. Standard errors are clustered by destination-reference importing country and year. Applied tariff is the tetradic term of the logarithm of applied tariff plus one. Columns (2) and (5) present estimations on the sample of non-MFN destinations and columns (3) and (6) on the sample of EU destination countries. ${ }^{a},{ }^{b}$ and ${ }^{c}$ denote statistical significance levels of one, five and ten percent respectively.

\section{A.8.3.. Selection bias}

Not all firms export to all markets $n$, and the endogenous selection into different export destinations across firms is one of the core elements of the type of model we are using. To understand the potential selection bias associated with estimating the trade elasticity it is useful to recall the firmlevel export equation (3), now accounting for the fact that we have exporters from both China and France, and therefore using the export country index $i$ :

$$
\ln x_{n i}(\alpha)=(1-\sigma) \ln \left(\frac{\sigma}{\sigma-1}\right)+(1-\sigma) \ln \left(\alpha w_{i}\right)+(1-\sigma) \ln \tau_{n i}+\ln A_{n}+\ln \epsilon_{n i}(\alpha)
$$


In this model, selection is due to the presence of a fixed export cost $f_{n i}$ that makes some firms unprofitable in some markets. Assuming that fixed costs are paid using labor of the origin country, profits in this setup are given by $x_{n i}(\alpha) / \sigma-w_{i} f_{n i}$, which means that a firm is all the more likely to be present in market $n$ that its $(1-\sigma) \ln \left(\alpha w_{i}\right)+(1-\sigma) \ln \tau_{n i}+\ln A_{n}+\ln \epsilon_{n i}(\alpha)$ is high. Therefore a firm with a low cost $\left(\alpha w_{i}\right)$ can afford having a low draw on $\epsilon_{n i}(\alpha)$, creating a systematic bias on the cost variable. The same logic applies in attractive markets, (high $A_{n}$ ), which will be associated with lower average draws on the error term. Fortunately, our tetrad estimation technique removes the need to estimate $\alpha w_{i}$ and $A_{n}$, and therefore solves this issue.

However a similar problem arises with the trade cost variable, $\tau_{n i}$, which is used to estimate the trade elasticity. Higher tariff countries will be associated with firms having drawn higher $\epsilon_{n i}(\alpha)$, thus biasing downwards our estimate of the trade elasticity. Our approach of tetrads that focuses on highly ranked exporters for each hs6-market combination should however not be too sensitive to that issue, since those are firms that presumably have such a large productivity that their idiosyncratic destination shock is of second order. In order to verify that intuition, we follow Eaton and Kortum (2001), applied to firm-level data by Crozet et al. (2012), who assume a normally distributed In $\epsilon_{n i}(\alpha)$, yielding a generalized structural tobit. This procedure uses the theoretical equation for minimum sales, $x_{n i}^{\mathrm{MIN}}(\alpha)=\sigma w_{i} f_{n i}$, which provides a natural estimate for the truncation point for each desination market. This method (EK tobit) keeps all individual exports to all possible destination markets (including zeroes). ${ }^{24}$ When estimating equation (A.1), we proxy for $\ln A_{n}$ with $\mathrm{GDP}_{n}$ and population $n$, and for firm-level determinants $\alpha$ with the count of markets served by the firm. An origin country dummy for Chinese exporters account for all differences across the two groups, such as wages, $w_{i}$. Last, we ensure comparability by i) keeping the same sample of productmarket combinations as in previous estimations using tetrads, ii) running the estimation with the same dimension of fixed effects (hs6). Each column of Tables A.8 and A.9 show the simple OLS (biased) estimates or the EK-tobit method run in the sample of product-market combinations by reference importing country. As in previous usages of that method, the OLS seems very severely biased, probably due to the extremely high selection levels observed (with all reference countries, slightly less than $14 \%$ of possible flows are observed). Strikingly, the EK tobit estimates are very comparable to the tetrad estimates shown until now, giving us further confidence in an order of magnitude of the firm-level trade elasticity around located between -4 and $-6 .{ }^{25}$

\footnotetext{
${ }^{24}$ For each product, we fill in with zero flows destinations that a firm found unprofitable to serve in reality. The set of potential destinations for that product is given all countries where at least one firm exported that good.

${ }^{25}$ Pooling over all the reference countries gives tariff elasticities of 1.893 for OLS and -4.925 for the EK tobit, both very significant. This pattern and those values are very much in line with detailed results from Tables A.8 and A.9.
} 
Table A.8 - Correcting for the selection bias.

\begin{tabular}{|c|c|c|c|c|c|c|c|c|}
\hline \multirow{3}{*}{ Ref. country: } & (1) & (2) & (3) & (4) & (5) & (6) & (7) & (8) \\
\hline & \multicolumn{2}{|c|}{ Australia } & \multicolumn{2}{|c|}{ Canada } & \multicolumn{2}{|c|}{ Germany } & \multicolumn{2}{|c|}{ Italy } \\
\hline & OLS & EK Tobit & OLS & EK Tobit & OLS & EK Tobit & OLS & EK Tobit \\
\hline Applied Tariff & $\begin{array}{c}1.26^{a} \\
(0.16)\end{array}$ & $\begin{array}{l}-6.28^{a} \\
(0.87)\end{array}$ & $\begin{array}{c}1.33^{a} \\
(0.18)\end{array}$ & $\begin{array}{l}-5.05^{a} \\
(0.93)\end{array}$ & $\begin{array}{c}2.09^{a} \\
(0.17)\end{array}$ & $\begin{array}{l}-3.78^{a} \\
(0.71)\end{array}$ & $\begin{array}{c}1.41^{a} \\
(0.16)\end{array}$ & $\begin{array}{l}-6.39^{a} \\
(0.74)\end{array}$ \\
\hline RTA & $\begin{array}{l}-0.67^{a} \\
(0.06)\end{array}$ & $\begin{array}{l}1.37^{a} \\
(0.33)\end{array}$ & $\begin{array}{l}-0.55^{a} \\
(0.06)\end{array}$ & $\begin{array}{l}2.36^{a} \\
(0.34)\end{array}$ & $\begin{array}{l}-0.63^{a} \\
(0.06)\end{array}$ & $\begin{array}{l}2.27^{a} \\
(0.31)\end{array}$ & $\begin{array}{l}-0.67^{a} \\
(0.05)\end{array}$ & $\begin{array}{l}2.42^{a} \\
(0.30)\end{array}$ \\
\hline Distance & $\begin{array}{c}0.01 \\
(0.02)\end{array}$ & $\begin{array}{l}-0.40^{a} \\
(0.13)\end{array}$ & $\begin{array}{c}0.05^{b} \\
(0.02)\end{array}$ & $\begin{array}{c}0.14 \\
(0.12)\end{array}$ & $\begin{array}{c}0.02 \\
(0.02)\end{array}$ & $\begin{array}{l}-0.21^{c} \\
(0.11)\end{array}$ & $\begin{array}{c}0.04^{b} \\
(0.02)\end{array}$ & $\begin{array}{l}-0.06 \\
(0.11)\end{array}$ \\
\hline Common language & $\begin{array}{c}0.07^{c} \\
(0.04)\end{array}$ & $\begin{array}{l}3.32^{a} \\
(0.20)\end{array}$ & $\begin{array}{c}0.30^{a} \\
(0.04)\end{array}$ & $\begin{array}{l}4.95^{a} \\
(0.23)\end{array}$ & $\begin{array}{c}0.21^{a} \\
(0.03)\end{array}$ & $\begin{array}{l}3.94^{a} \\
(0.17)\end{array}$ & $\begin{array}{c}0.22^{a} \\
(0.03)\end{array}$ & $\begin{array}{l}4.14^{a} \\
(0.17)\end{array}$ \\
\hline Contiguity & $\begin{array}{c}0.07^{b} \\
(0.03)\end{array}$ & $\begin{array}{l}1.55^{a} \\
(0.12)\end{array}$ & $\begin{array}{c}0.06^{b} \\
(0.03)\end{array}$ & $\begin{array}{c}1.23^{a} \\
(0.12)\end{array}$ & $\begin{array}{c}0.15^{a} \\
(0.02)\end{array}$ & $\begin{array}{c}1.91^{a} \\
(0.10)\end{array}$ & $\begin{array}{c}0.10^{a} \\
(0.02)\end{array}$ & $\begin{array}{l}1.85^{a} \\
(0.11)\end{array}$ \\
\hline Colony & $\begin{array}{c}0.64^{a} \\
(0.10)\end{array}$ & $\begin{array}{l}4.29^{a} \\
(0.55)\end{array}$ & $\begin{array}{c}0.69^{a} \\
(0.10)\end{array}$ & $\begin{array}{l}2.50^{a} \\
(0.55)\end{array}$ & $\begin{array}{c}0.85^{a} \\
(0.09)\end{array}$ & $\begin{array}{l}2.65^{a} \\
(0.43)\end{array}$ & $\begin{array}{c}0.79^{a} \\
(0.08)\end{array}$ & $\begin{array}{l}2.23^{a} \\
(0.43)\end{array}$ \\
\hline $\mathrm{GDP}_{n}$ & $\begin{array}{c}0.16^{a} \\
(0.01)\end{array}$ & $\begin{array}{l}1.57^{a} \\
(0.05)\end{array}$ & $\begin{array}{c}0.15^{a} \\
(0.01)\end{array}$ & $\begin{array}{l}1.84^{a} \\
(0.06)\end{array}$ & $\begin{array}{c}0.19^{a} \\
(0.01)\end{array}$ & $\begin{array}{l}1.65^{a} \\
(0.05)\end{array}$ & $\begin{array}{c}0.16^{a} \\
(0.01)\end{array}$ & $\begin{array}{l}1.48^{a} \\
(0.05)\end{array}$ \\
\hline Population $_{n}$ & $\begin{array}{c}0.03^{b} \\
(0.01)\end{array}$ & $\begin{array}{l}0.71^{a} \\
(0.06)\end{array}$ & $\begin{array}{c}0.07^{a} \\
(0.02)\end{array}$ & $\begin{array}{c}0.61^{a} \\
(0.07)\end{array}$ & $\begin{array}{c}0.02 \\
(0.01)\end{array}$ & $\begin{array}{l}0.67^{a} \\
(0.05)\end{array}$ & $\begin{array}{c}0.04^{a} \\
(0.01)\end{array}$ & $\begin{array}{l}0.84^{a} \\
(0.06)\end{array}$ \\
\hline Chinese exporter dummy & $\begin{array}{c}0.26^{a} \\
(0.03)\end{array}$ & $\begin{array}{l}0.44^{a} \\
(0.13)\end{array}$ & $\begin{array}{c}0.39^{a} \\
(0.04)\end{array}$ & $\begin{array}{l}0.58^{a} \\
(0.16)\end{array}$ & $\begin{array}{c}0.51^{a} \\
(0.03)\end{array}$ & $\begin{array}{l}1.44^{a} \\
(0.15)\end{array}$ & $\begin{array}{c}0.37^{a} \\
(0.03)\end{array}$ & $\begin{array}{l}1.11^{a} \\
(0.14)\end{array}$ \\
\hline \# of dest. by firm & $\begin{array}{c}0.19^{a} \\
(0.01)\end{array}$ & $\begin{array}{l}2.06^{a} \\
(0.03)\end{array}$ & $\begin{array}{c}0.14^{a} \\
(0.01)\end{array}$ & $\begin{array}{l}1.98^{a} \\
(0.03)\end{array}$ & $\begin{array}{c}0.13^{a} \\
(0.01)\end{array}$ & $\begin{array}{c}1.96^{a} \\
(0.03)\end{array}$ & $\begin{array}{l}0.14^{a} \\
(0.01)\end{array}$ & $\begin{array}{l}2.04^{a} \\
(0.03)\end{array}$ \\
\hline Observations & 617231 & 5518719 & 571508 & 4386238 & 730720 & 5828685 & 735346 & 5917116 \\
\hline $\begin{array}{l}R^{2} \\
\text { Pseudo } R^{2}\end{array}$ & 0.058 & 0.082 & 0.051 & 0.086 & 0.059 & 0.075 & 0.053 & 0.077 \\
\hline
\end{tabular}

Notes: All estimations include fixed effects for each hs6 product level. Standard errors are clustered at the hs6destination-origin country level. Applied tariff is the logarithm of applied tariff plus one at the hs6 product level and destination country. $\mathrm{a}, \mathrm{b}$ and $\mathrm{c}$ denote statistical significance levels of one, five and ten percent respectively. 
Table A.9 - Correcting for the selection bias.(cont.)

\begin{tabular}{|c|c|c|c|c|c|c|c|c|}
\hline \multirow{3}{*}{ Ref. country: } & (1) & (2) & (3) & (4) & (5) & (6) & (7) & (8) \\
\hline & \multicolumn{2}{|c|}{ Japan } & \multicolumn{2}{|c|}{ UK } & \multicolumn{2}{|c|}{ New Zealand } & \multicolumn{2}{|c|}{ Poland } \\
\hline & OLS & EK Tobit & OLS & EK Tobit & OLS & EK Tobit & OLS & EK Tobit \\
\hline Applied Tariff & $\begin{array}{l}1.13^{a} \\
(0.23)\end{array}$ & $\begin{array}{l}-5.45^{a} \\
(1.09)\end{array}$ & $\begin{array}{l}1.73^{a} \\
(0.16)\end{array}$ & $\begin{array}{l}-4.99^{a} \\
(0.78)\end{array}$ & $\begin{array}{c}0.62^{a} \\
(0.22)\end{array}$ & $\begin{array}{l}-4.34^{a} \\
(1.14)\end{array}$ & $\begin{array}{c}1.22^{a} \\
(0.20)\end{array}$ & $\begin{array}{l}-4.60^{a} \\
(0.87)\end{array}$ \\
\hline RTA & $\begin{array}{l}-0.28^{a} \\
(0.08)\end{array}$ & $\begin{array}{l}3.12^{a} \\
(0.37)\end{array}$ & $\begin{array}{l}-0.73^{a} \\
(0.05)\end{array}$ & $\begin{array}{l}2.62^{a} \\
(0.29)\end{array}$ & $\begin{array}{l}-0.51^{a} \\
(0.08)\end{array}$ & $\begin{array}{l}1.65^{a} \\
(0.40)\end{array}$ & $\begin{array}{l}-0.52^{a} \\
(0.08)\end{array}$ & $\begin{array}{l}1.98^{a} \\
(0.35)\end{array}$ \\
\hline Distance & $\begin{array}{l}0.18^{a} \\
(0.03)\end{array}$ & $\begin{array}{c}0.38^{a} \\
(0.13)\end{array}$ & $\begin{array}{l}0.05^{a} \\
(0.02)\end{array}$ & $\begin{array}{l}-0.08 \\
(0.11)\end{array}$ & $\begin{array}{l}0.07^{b} \\
(0.03)\end{array}$ & $\begin{array}{l}-0.18 \\
(0.14)\end{array}$ & $\begin{array}{c}0.08^{a} \\
(0.03)\end{array}$ & $\begin{array}{l}-0.03 \\
(0.12)\end{array}$ \\
\hline Common language & $\begin{array}{l}0.28^{a} \\
(0.04)\end{array}$ & $\begin{array}{l}3.70^{a} \\
(0.20)\end{array}$ & $\begin{array}{c}0.25^{a} \\
(0.03)\end{array}$ & $\begin{array}{l}4.31^{a} \\
(0.16)\end{array}$ & $\begin{array}{c}0.31^{a} \\
(0.06)\end{array}$ & $\begin{array}{l}4.01^{a} \\
(0.29)\end{array}$ & $\begin{array}{c}0.25^{a} \\
(0.05)\end{array}$ & $\begin{array}{l}4.21^{a} \\
(0.24)\end{array}$ \\
\hline Contiguity & $\begin{array}{c}0.02 \\
(0.03)\end{array}$ & $\begin{array}{l}1.46^{a} \\
(0.13)\end{array}$ & $\begin{array}{c}0.14^{a} \\
(0.02)\end{array}$ & $\begin{array}{l}1.31^{a} \\
(0.11)\end{array}$ & $\begin{array}{c}0.03 \\
(0.04)\end{array}$ & $\begin{array}{l}1.67^{a} \\
(0.19)\end{array}$ & $\begin{array}{c}0.09^{b} \\
(0.04)\end{array}$ & $\begin{array}{l}1.75^{a} \\
(0.16)\end{array}$ \\
\hline Colony & $\begin{array}{l}0.56^{a} \\
(0.11)\end{array}$ & $\begin{array}{l}3.91^{a} \\
(0.79)\end{array}$ & $\begin{array}{c}0.73^{a} \\
(0.08)\end{array}$ & $\begin{array}{l}2.51^{a} \\
(0.51)\end{array}$ & $\begin{array}{l}0.64^{a} \\
(0.11)\end{array}$ & $\begin{array}{l}4.17^{a} \\
(0.98)\end{array}$ & $\begin{array}{l}0.71^{a} \\
(0.09)\end{array}$ & $\begin{array}{l}3.41^{a} \\
(0.57)\end{array}$ \\
\hline $\mathrm{GDP}_{n}$ & $\begin{array}{l}0.13^{a} \\
(0.01)\end{array}$ & $\begin{array}{l}1.71^{a} \\
(0.07)\end{array}$ & $\begin{array}{c}0.17^{a} \\
(0.01)\end{array}$ & $\begin{array}{l}1.57^{a} \\
(0.05)\end{array}$ & $\begin{array}{l}0.14^{a} \\
(0.02)\end{array}$ & $\begin{array}{l}1.80^{a} \\
(0.08)\end{array}$ & $\begin{array}{c}0.19^{a} \\
(0.02)\end{array}$ & $\begin{array}{l}1.58^{a} \\
(0.07)\end{array}$ \\
\hline Population $_{n}$ & $\begin{array}{l}0.09^{a} \\
(0.02)\end{array}$ & $\begin{array}{l}0.73^{a} \\
(0.08)\end{array}$ & $\begin{array}{c}0.03^{b} \\
(0.01)\end{array}$ & $\begin{array}{c}0.71^{a} \\
(0.06)\end{array}$ & $\begin{array}{c}0.08^{a} \\
(0.02)\end{array}$ & $\begin{array}{l}0.52^{a} \\
(0.09)\end{array}$ & $\begin{array}{c}0.02 \\
(0.02)\end{array}$ & $\begin{array}{l}0.59^{a} \\
(0.07)\end{array}$ \\
\hline Chinese exporter dummy & $\begin{array}{l}0.21^{a} \\
(0.04)\end{array}$ & $\begin{array}{l}1.10^{a} \\
(0.15)\end{array}$ & $\begin{array}{c}0.40^{a} \\
(0.03)\end{array}$ & $\begin{array}{l}1.40^{a} \\
(0.14)\end{array}$ & $\begin{array}{l}0.15^{a} \\
(0.04)\end{array}$ & $\begin{array}{c}0.10 \\
(0.20)\end{array}$ & $\begin{array}{c}0.34^{a} \\
(0.05)\end{array}$ & $\begin{array}{l}1.08^{a} \\
(0.18)\end{array}$ \\
\hline \# of dest. by firm & $\begin{array}{l}0.18^{a} \\
(0.01)\end{array}$ & $\begin{array}{l}1.91^{a} \\
(0.03)\end{array}$ & $\begin{array}{l}0.14^{a} \\
(0.01)\end{array}$ & $\begin{array}{l}1.95^{a} \\
(0.03)\end{array}$ & $\begin{array}{c}0.25^{a} \\
(0.01)\end{array}$ & $\begin{array}{l}2.43^{a} \\
(0.05)\end{array}$ & $\begin{array}{c}0.22^{a} \\
(0.01)\end{array}$ & $\begin{array}{l}2.18^{a} \\
(0.04)\end{array}$ \\
\hline $\begin{array}{l}\text { Observations } \\
R^{2}\end{array}$ & 414135 & 2732178 & 735485 & 5901262 & 343141 & 2864115 & 361503 & 2891673 \\
\hline$R^{2}$ & 0.046 & & 0.061 & & 0.048 & & 0.052 & \\
\hline
\end{tabular}

Notes: All estimations include fixed effects for each hs6 product level. Standard errors are clustered at the hs6destination-origin country level. Applied tariff is the logarithm of applied tariff plus one at the hs6 product level and destination country. $\mathrm{a}, \mathrm{b}$ and $\mathrm{c}$ denote statistical significance levels of one, five and ten percent respectively. 


\section{A.8.4.. Non-constant trade elasticity}

Table A.10 - Non-constant trade elasticity

\begin{tabular}{lccc|ccc}
\hline & \multicolumn{3}{|c|}{2000} & \multicolumn{3}{c}{2006} \\
\hline Dependent variable: & Tot. & \# exp. & Avg. & Tot. & $\#$ exp. & Avg. \\
\hline & $(1)$ & $(2)$ & $(3)$ & $(4)$ & $(5)$ & $(6)$ \\
\hline \multirow{3}{*}{ Applied Tariff } & & & & & & \\
& $-5.74^{a}$ & $-3.41^{a}$ & $-2.34^{a}$ & $-4.31^{a}$ & $-3.52^{a}$ & $-0.79^{b}$ \\
& $(1.02)$ & $(0.69)$ & $(0.72)$ & $(0.53)$ & $(0.57)$ & $(0.37)$ \\
Applied Tariff $_{n, \mathrm{CN}}$ & $5.08^{a}$ & $2.55^{a}$ & $2.53^{a}$ & $2.16^{a}$ & $1.55^{a}$ & 0.61 \\
& $(0.99)$ & $(0.71)$ & $(0.66)$ & $(0.57)$ & $(0.58)$ & $(0.38)$ \\
\hline Observations & 99745 & 99745 & 99745 & 218036 & 218036 & 218036 \\
$R^{2}$ & 0.357 & 0.590 & 0.093 & 0.339 & 0.594 & 0.072 \\
rmse & 2.42 & 1.00 & 2.02 & 2.34 & 0.98 & 2.01 \\
\hline \hline
\end{tabular}

Notes: All estimations include a product and reference country fixed effects and the four components ( $n F R, n C N, k F R$, and $k C N$ ) of each gravity control (distance, common language, contiguity and colony). In all estimations standard errors are clustered at the destination-reference country.

\section{Appendix 9:. Theoretical Mean-to-Min ratios under Pareto and Log-Normal distributions}

In general, the shape of the distribution of firms' productivity matters for the aggregate trade elasticity, generating heterogeneous responses across country pairs to the same trade costs shock In this Appendix we consider two different distributions of the (rescaled) productivity: i) Pareto, which turns out to be a quite special case where heterogeneity washes out, and ii) Log-normal which maintains the mapping between heterogeneous productivity and heterogeneous trade elasticities.

More precisely, the central relationship (13) makes it clear that the heterogeneity of aggregate trade elasticity comes entirely from the term $\gamma_{n i}$ that stems from endogenous selection of firms into export markets (see equation 14). In turn, $\gamma_{n i}$ depends on the cost-performance index $V_{n i}$ as defined by (11). We therefore need to understand how these $\gamma$ and $V$ terms behave under alternative distribution assumptions.

If productivity is Pareto then the rescaled unit input requirement a has PDF $g(a)=\theta a^{\theta-1} / \bar{a}^{\theta}$, which translates into

$$
V_{n i}^{\mathrm{P}}=\frac{\theta a_{n i}^{* \theta-\sigma+1}}{\bar{a}^{\theta}(\theta-\sigma+1)}
$$

The elasticity of $V_{n i}$ with respect to $a^{*}$ is

$$
\gamma_{n i}^{\mathrm{P}}=\theta-\sigma+1>0
$$


Hence, Pareto makes all the $\gamma_{n i}$ terms be the same, and therefore transforms an expression generally yielding heterogeneous trade elasticities into a one-parameter elasticity $\frac{d \ln X_{n i}}{d \ln \tau_{n i}}=\theta$, that is related to the supply side of the economy only.

When productive efficiency is distributed log-normally, things are very different. For $\varphi \sim \log$ $\mathcal{N}(\mu, \nu)$, the distribution of rescaled unit input requirements is a $\sim \log -\mathcal{N}(-\mu, \nu)$, and we can write

$$
V_{n i}^{\mathrm{LN}}=\exp \left[(\sigma-1) \mu+(\sigma-1)^{2} \nu^{2} / 2\right] \Phi\left[\left(\ln a_{n i}^{*}+\mu\right) / \nu+(\sigma-1) \nu\right],
$$

where $\Phi()$ denotes the CDF of the standard normal distribution. Differentiating $\ln V_{n i}$ with respect to $\ln a_{n i}^{*}$,

$$
\gamma_{n i}^{\mathrm{LN}}=\frac{1}{\nu} h\left(\frac{\ln a_{n i}^{*}+\mu}{\nu}+(\sigma-1) \nu\right),
$$

where $h(x) \equiv \phi(x) / \Phi(x)$, the ratio of the PDF to the CDF of the standard normal. Thus $\gamma_{n i}$ is no longer the constant $1-\sigma+\theta$ which obtains for productivity distibuted Pareto with shape parameter $\theta$.

The $\mathcal{H}$ function is a central element of our calibration procedure, as summarized by relationship (16) , that reveals cutoffs and therefore aggregate bilateral elasticities. Comparing (11), (14) and (15) we see that $\mathcal{H}$ and $\gamma$ are closely related

$$
\gamma_{n i} \times \mathcal{H}\left(a_{n i}^{*}\right)=a_{n i}^{*} \frac{g\left(a_{n i}^{*}\right)}{G\left(a_{n i}^{*}\right)}
$$

With Pareto, we make use of (A.3) to obtain

$$
\mathcal{H}^{\mathrm{P}}\left(a_{n i}^{*}\right)=\frac{\theta}{\theta-\sigma+1},
$$

With a log-normal productivity, equation (A.5) leads to

$$
\mathcal{H}^{\mathrm{LN}}\left(a_{n i}^{*}\right)=\frac{h\left[\left(\ln a_{n i}^{*}+\mu\right) / \nu\right]}{h\left[\left(\ln a_{n i}^{*}+\mu\right) / \nu+(\sigma-1) \nu\right]},
$$

An attractive feature of our quantification procedure relates to the small number of relevant parameters to be calibrated. Under Pareto, equations (A.3) and (A.7) show that only the shape parameter $\theta$ matters. Similarly, under a log-normal, only the calibration of the second-moment of the distribution, $\nu$, is necessary for inverting the $\mathcal{H}$ function to reveal the cutoff and for quantifying the aggregate elasticity: This last point stems from the fact that shifting the first moment, $\mu$, affects (A.5) and (A.8) in an identical way and so has no impact on the quantification. 


\section{Appendix 10:. Monte Carlo Simulations}

In Section 5.3 we find that the macro-based estimate of the aggregate trade elasticity is quantitatively close to the cross-dyadic average of the micro-based estimates when heterogeneity is calibrated as being log-normal. We interpret this finding as an empirical support in favor of this distributional assumption. In this section we substantiate this last statement by embracing a more theoretical perspective. This is an important step in the argument because the theoretical relationship between the macro- and the micro-based estimates of the elasticities is unknown (except under Pareto where they are unambiguously equal). Hereafter we provide simulation-based evidence that the similarity between micro- and macro-based estimates is not accidental, even under log-normal heterogeneity.

We proceed with Monte Carlo (MC) simulations of our generic trade model with heterogeneous firms. In the baseline simulations we generate fake bilateral trade for 10 countries and 1 million active firms per country. Our data generating process uses the firms' sales in equation (2). Firmlevel heterogeneity in terms of rescaled labor requirement, $a \equiv \alpha \times b(\alpha)$ is assumed to be Pareto or Log-normally distributed with a set of parameters identical to the ones used in our empirical analysis (section 5.2). We also retain $\sigma=5$ as the parameter for the intensive margin. Without loss of generality, in this partial equilibrium framework, we normalize the nominal wage, $w=1$, and we draw $A_{n} / f_{n i}$, i.e. the dyadic ratio of destination $n$ attractiveness over entry cost from a log-normal distribution. This distribution is calibrated such as to match an average dyadic share of exporting firms of 10 percent. Finally the applied-tariffs $\tau_{n i}=1+t_{n i}$ are drawn from an uniform distribution over the range $[1,2]$.

In each MC draw, we first generate a matrix of firm-level trade flows that are non-zero when sales exceed the bilateral entry cost, i.e. $x_{n i}(a)>\sigma w f_{n i}$. In a first stage we infer from this fake trade dataset the micro-based estimates of the aggregate trade elasticities by applying the methodology of Section 5.2: We first retrieve min-to-mean ratios for all country-pairs and then compute the corresponding set of theoretical dyadic elasticities (equations 17 and 18). In a second stage, we turn to the macro-based estimates of the trade elasticity. To this purpose we collapse firm-level trade flows at the country-pair level to construct a matrix of bilateral aggregate trade. We then run gravity regressions (both using country fixed effects and tetrads) and retrieve the point estimate of applied tariffs. Hence, for each draw, we obtain one macro-based estimate of the trade elasticity that we compare to the cross-dyadic average of the micro-based elasticities. This procedure is replicated 50 times. Notice that it is computationally demanding as we have to manipulate very large trade matrices $(1$ million firms $\times 10$ origin countries $\times 10$ destination countries) .

The simulation results are displayed in Table A.11 for log-normal (col.1-col.4) and Pareto (col.5col.8) and for different degrees of firm scarceness (from 1000 to 1 million firms per country). Each column reports averages and standard errors across replications.

Our baseline simulation under Pareto (col. 8) shows that the simulated economy with 1 million firms conforms to the theoretical prediction of a model with a continuum of firms. The micro-based 
Table A.11 - Monte Carlo results: elasticities wrt to a change in trade costs

\begin{tabular}{lcccc|cccc}
\hline Distribution: & \multicolumn{4}{c|}{ Log-Normal } & \multicolumn{5}{c}{ Pareto } \\
\hline \# firms per country: & $1 \mathrm{~K}$ & $10 \mathrm{~K}$ & $100 \mathrm{~K}$ & $1 \mathrm{M}$ & $1 \mathrm{~K}$ & $10 \mathrm{~K}$ & $100 \mathrm{~K}$ & $1 \mathrm{M}$ \\
\hline \multirow{2}{*}{ total exports (micro) } & -4.69 & -4.57 & -4.56 & -4.55 & -5.74 & -5.36 & -5.23 & -5.18 \\
& $(0.60)$ & $(0.38)$ & $(0.34)$ & $(0.33)$ & $(0.87)$ & $(0.37)$ & $(0.21)$ & $(0.13)$ \\
total exports (macro/tetrads) & -4.80 & -4.60 & -4.59 & -4.58 & -5.55 & -5.37 & -5.21 & -5.18 \\
& $(0.66)$ & $(0.29)$ & $(0.09)$ & $(0.03)$ & $(0.81)$ & $(0.56)$ & $(0.35)$ & $(0.22)$ \\
total exports (macro/FE) & -4.65 & -4.57 & -4.55 & -4.55 & -5.59 & -5.31 & -5.22 & -5.17 \\
& $(0.20)$ & $(0.09)$ & $(0.03)$ & $(0.01)$ & $(0.29)$ & $(0.16)$ & $(0.15)$ & $(0.08)$ \\
nb exporters (macro/FE) & -3.20 & -3.16 & -3.16 & -3.16 & -5.19 & -5.15 & -5.14 & -5.13 \\
& $(0.09)$ & $(0.03)$ & $(0.01)$ & $(0.00)$ & $(0.13)$ & $(0.05)$ & $(0.02)$ & $(0.01)$ \\
avg. exports (macro/FE) & -1.45 & -1.41 & -1.40 & -1.39 & -0.40 & -0.15 & -0.08 & -0.04 \\
& $(0.17)$ & $(0.08)$ & $(0.03)$ & $(0.01)$ & $(0.26)$ & $(0.16)$ & $(0.15)$ & $(0.08)$ \\
& & & & & & & & \\
\hline \hline
\end{tabular}

Notes: 50 replications for each cell, parameters on fixed costs of exports and size of the demand term have been calibrated so the share of exporters averages to $10-11 \%$ in all simulations. For each elasticity, the first line reports the average value. Standard deviations are in parentheses. For the micro elasticity, the number in parentheses is the average of standard deviations of the elasticity in each draw (quantifying the degree of heterogeneity in bilateral elasticities). For the macro elasticities, we report the standard deviation of elasticities across the 50 replications.

estimates of the aggregate trade elasticity are relatively homogeneous across dyads (the second row reports the mean value of the standard deviation within each draw) and their average (first row) is close to the macro-based estimates of the elasticities retrieved from tetrad-like specification (third row) or standard gravity (fourth row). Finally the elasticity of the average export (last row) is not significantly different from zero, as expected from the theoretical prediction associated with Pareto heterogeneity and a continuum of firms. We conclude from this exercise that scarceness does not seem to play a central role in our fake sample of 1 million firms with 10 percent of exporters.

From the baseline simulation under log-normal (Column 4) we see that the macro-based estimate of the aggregate elasticity and the cross-dyadic average of the micro-based estimates are quantitatively very close - i.e. equality cannot be rejected. This constitutes the main result of our Monte Carlo approach. It confirms that the similarity between micro- and macro-based estimates in section 5.3 can be safely interpreted as supportive of the log-normal distribution. Notice that the magnitude of the simulation results on the three macro-based elasticities (total exports, count of exporters and average exports) is also close to what we obtain with the sample of French and Chinese firms. This is remarkable given that our Monte Carlo approach is minimal and shares only few features with the true data, i.e. the parameters of firm-level heterogeneity and the share of exporters. 